\title{
Dinámica territorial de pandemia COVID-19 en la provincia de Córdoba (Argentina)
}

\author{
Territorial dynamics of the COVID-19 pandemic \\ in the province of Córdoba, Argentina
}

\author{
Luciana Buffalo \\ lubuffalo@gmail.com \\ Laboratorio de estudios territoriales \\ Universidad Nacional de Córdoba (Argentina) \\ Ana Laura Rydzewski \\ analaurarydzewski@gmail.com \\ Instituto Nacional del Agua (Argentina) \\ Universidad Nacional de Córdoba (Argentina)
}

\section{Resumen}

En este artículo, se analiza la distribución de casos en el territorio de la provincia de Córdoba Argentina, entre marzo y noviembre del 2020, en relación a las políticas implementadas de aislamiento y flexibilización articulados con las prácticas sociales con incidencia en la circulación de la enfermedad. En la provincia de Córdoba, la enfermedad ha seguido un patrón variable en términos temporales, pero con similitudes espaciales asociadas a características territoriales que actúan como condicionantes, y a políticas públicas de restricción de actividades productivas y movilidad, que repercutieron en la dinámica de la pandemia. El diseño metodológico de análisis espacial, se realizó a partir de un sistema de información geográfica basado en el uso de software libre (Qgis) que permitió trabajar con la localización de casos diagnosticados con la 
COVID-19, su temporalidad y al mismo tiempo asociar ese análisis, con información cualitativa y cuantitativa de las características del territorio provincial (áreas comerciales, situación demográfica, características socio económicas de la población, instituciones para adultos mayores, entre otras). El análisis realizado, con cartografía espacio- temporal permitió generar información para la toma de decisiones en el ámbito público en tiempo real, articulando el conocimiento geográfico con la epidemiología y la estadística aplicada a la salud.

Palabras clave: dinámica territorial; análisis espacial; espacio-tiempo.

\begin{abstract}
In this article, is analyzed the distribution of cases COVID-19 in the territory of the province of Córdoba Argentina, between March and November 2020, in relation to the implemented policies of isolation and flexibility articulated with social practices that affect the circulation of the disease. In the province of Córdoba, the disease has followed a variable pattern in temporal terms, but with spatial similarities associated with territorial characteristics that act as conditioning factors and public policies restricting productive activities and mobility, which had an impact on the dynamics of the pandemic. The methodological design of spatial analysis was carried out from a geographic information system based on the use of free software (Qgis) that allowed working with the location of positive COVID cases, their temporality and at the same time associating that analysis with information qualitative and quantitative of the characteristics of the provincial territory (commercial areas, demographic situation, socio-economic characteristics of the population, institutions for the elderly, among others). The analysis carried out, accompanied by time-space cartography, made it possible to generate information for decision-making in the public sphere in real time, articulating geographic knowledge with epidemiology and statistics applied to health.
\end{abstract}

Key words: territorial dynamics; spatial analysis; space-time.

\title{
1 Introducción
}

La COVID-19 es una enfermedad causada por el virus SARS-CoV-2, que se propaga a través de de las vías respiratorias por contacto con gotículas o aerosoles producidos por una persona infectada al entrar en contacto con la nariz, boca u ojos de una persona sana. El 11 de marzo de 2020, ante la rápida y progresiva expansión de la epidemia a nivel internacional la Organización mundial de la salud (OMS) decretó el estado de pandemia. Desde entonces, el $90 \%$ de los 
casos registrados corresponden a zonas urbanas, si bien no existe un vínculo directo entre densidad poblacional y nivel de contagios, la OMS identifica a la concentración de población, movilidad de las personas e intercambios (locales e internacionales) como los factores que las hacen especialmente vulnerables a la propagación del virus (OMS 2020).

En Argentina el primer caso se detecta el 3 de marzo de 2020 (MSN 2020). Posteriormente, el día 12 de marzo a partir de un Decreto de Necesidad y Urgencia (DNU 260/2020), el gobierno nacional declaro el estado de pandemia y en consonancia con las recomendaciones de la OMS, implemento medidas tendientes a proteger a la población y a disminuir la circulación viral. Para ello establecio restricciones a la movilidad de las personas, cierres de actividades económicas comerciales de servicios e industriales, sumado a políticas de salud orientadas a reforzar el sistema sanitario en la respuesta y detección de casos. A partir del 20 de marzo, se aplicó una medida de aislamiento social obligatorio (ASPO) para todo el territorio nacional, que fue concebida en cuatro etapas progresivas: aislamiento estricto, administrado con flexibilizaciones parciales de actividades, segmentación geográfica, reapertura progresiva; que finalmente culminaría con un retorno a la normalidad.

La etapa de aislamiento estricto rige desde el 20 al 31 de marzo de 2020. Durante el mismo la movilidad de las personas se restringe a comercios de proximidad en un contexto en donde solo estaban permitidas las actividades económicas esenciales vinculadas a la salud, alimentación y seguridad. A 31 de marzo los casos registrados en el país ascendían a 1504 de los cuales el 76,75\% correspondía a las provincias limítrofes de Buenos Aires, Córdoba, Santa Fe y a la Capital Federal.

Desde el 1 abril inicia un proceso de flexibilización que permite la apertura de actividades no esenciales, desde entonces se implementaron cierres y controles de circulación entre localidades en función del número de casos detectados. La aplicación de las medidas sanitarias estuvo a cargo de los gobiernos provinciales en consonancia con las disposiciones nacionales.

El trabajo que aquí se presenta, surge de la articulación interinstitucional del Ministerio de Salud de la Provincia de Córdoba (Secretaría de prevención y promoción de la salud) con la Universidad Pública, ante la necesidad de contar con información cartográfica para implementar acciones de monitoreo y contención del contagio de Sars-Cov-2, en una de las provincias que presentó una mayor incidencia de casos a nivel nacional durante el inicio de la pandemia. Su objetivo es analizar la dinámica de propagación espacio-temporal de la pandemia en la provincia 
de Córdoba a escala intraurbana y regional para el periodo marzo-noviembre del año 2020. Para el logro del objetivo general se definieron los siguientes objetivos específicos:

- Determinar áreas de mayor circulación de personas enfermas a escala intraurbana.

- Establecer patrones de distribución espacial de casos a escala urbana.

- Detectar e identificar áreas de recurrencia de aparición de casos según agregados zonales y redes de circulación.

Los resultados y análisis obtenidos aportaron información diaria, semanal y mensual que fueron utilizados por el ministerio de salud de la provincia de Córdoba para implementar acciones de monitoreo y control de propagación del virus.

El artículo se estructura en cinco apartados: una Introducción donde se plantea la problemática, los objetivos, y se incluye una descripción del área de estudio; consideraciones teóricas y antecedentes sobre el tema, estrategia metodológica utilizada para abordar los objetivos, resultados y conclusiones.

\subsection{Descripción del área de estudio}

La república Argentina posee una distribución desigual de su población en el territorio, el 62 \% se concentra en tres provincias limítrofes; Buenos Aires, Córdoba y Santa Fe, en una superficie que no alcanza el $22 \%$ del total del país. Los habitantes de la provincia de Buenos Aires representan el 38,95\% del total nacional, de los cuales el 24,72\% corresponde al área metropolitana del Gran Buenos Aires, y el 7,20 \% a la Capital Federal de la República. Le siguen en magnitud las provincias vecinas de Córdoba y Santa Fe que representan el 8,25 y 7,96 \% de la población nacional respectivamente (CNPHYV, 2010). En conjunto, desde el inicio de la pandemia, estas unidades territoriales fueron las que presentaron una mayor incidencia de casos a nivel nacional.

La provincia de Córdoba, presenta una estructura política administrativa que divide al territorio en 26 departamentos; compuestos por ciudades, municipios y comunas, en función de la cantidad de habitantes. Las primeras, deben poseer más de 10000 hab., lo que las habilita a dictar su propia carta orgánica, los municipios deben superar los 2000 hab., y las comunas un número inferior a éstos. Cada departamento posee una localidad cabecera, allí se ubican las principales sedes administrativas, jurídicas y establecimientos de salud de mayor complejidad. Del conjunto de departamentos, Capital es el único compuesto por una sola ciudad, que constituye la capital provincial denominada Ciudad de Córdoba. Al año 2020 presentaría, según 
las proyecciones de población, 1460905 hab. (INDEC, 2020). En cuanto a la distribución de la población al interior provincial, el gran Córdoba o área metropolitana Córdoba concentra $54,25 \%$ de población urbana de la provincia. Se compone de 42 localidades alrededor de la Capital en un radio inferior a los $50 \mathrm{~km}$, que registran un mayor crecimiento demográfico que la capital desde el año 1980 (Tecco, 2001). Le siguen en importancia los aglomerados urbanos de Río Cuarto, Villa María, Carlos Paz y San Francisco (Tabla 1).

Tabla 1. Ranking de ciudades con mayor población en la provincia y variación intercensal

\begin{tabular}{|l|c|c|c|}
\hline \multicolumn{1}{|c|}{ CIUDAD } & CENSO 2001 & CENSO 2010 & VARIACIÓN RELATIVA \\
\hline Córdoba & 1284582 & 1329604 & $3,50 \%$ \\
\hline Rio Cuarto & 144021 & 158298 & $9,90 \%$ \\
\hline Villa María & 72162 & 80006 & $10,90 \%$ \\
\hline Villa Carlos Paz & 56407 & 62750 & $11,20 \%$ \\
\hline San Francisco & 58779 & 62211 & $5,80 \%$ \\
\hline Alta Gracia & 42538 & 48506 & $14,00 \%$ \\
\hline Rio Tercero & 44715 & 46800 & $4,70 \%$ \\
\hline Bell Ville & 32066 & 34439 & $7,40 \%$ \\
\hline La Calera & 25655 & 32227 & $25,60 \%$ \\
\hline Jesús María & 26825 & 31864 & $18,80 \%$ \\
\hline
\end{tabular}

Fuente: elaboración propia en base a los CNPHV $(2001,2010)$

Al interior de las localidades existen subdivisiones territoriales menores denominadas barrios que constituyen zonas con límites definidos en función del loteo que les dio origen, dependiendo de la normativa de usos de suelo pueden presentar actividades mixtas residencial - comercial industrial, o ser exclusivamente de uso residencial.

La distribución de la población en áreas urbanas y el nivel de jerarquía de infraestructura y servicios que ellas presentan, se encuentra condicionada por dos ejes estructurantes históricos radiocéntricos: el ferrocarril a partir del cual se desarrollaron localidades en torno a las estaciones, y posteriormente las rutas nacionales, que son paralelas a los ramales ferroviarios. Ambas vías de comunicación responden a la centralidad del comercio en las ciudades de Rosario (provincia de Santa Fe) y Buenos Aires que contienen los principales puertos del sistema 
fluvial, y además es por donde circulan los mayores volúmenes de cargas para consumo interno, así como de exportación e importación por los corredores bioceánicos de integración con el continente sudamericano (Figura 1).

Figura 1. Ubicación regional, localidades, red vial y jerarquía urbana
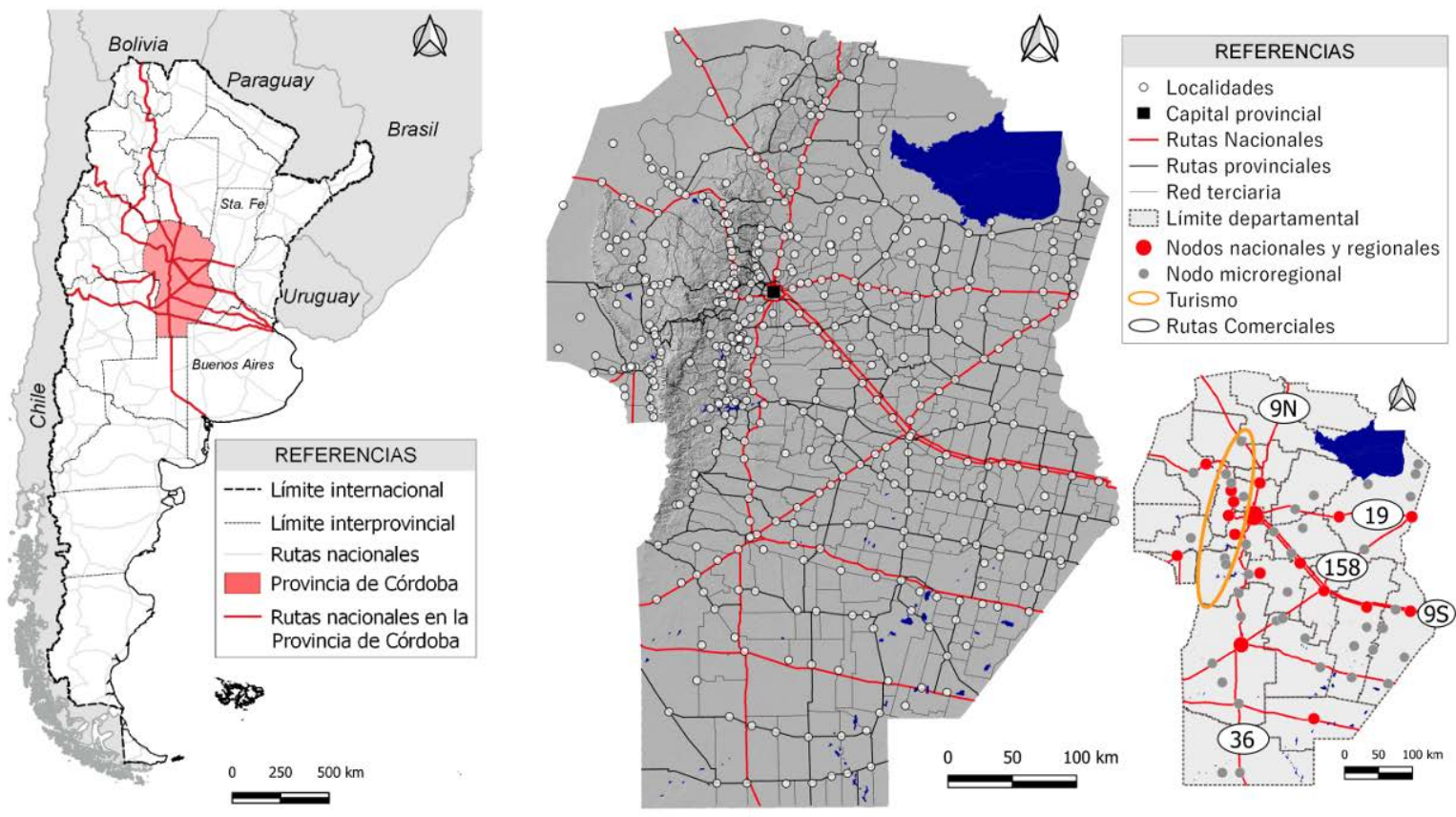

Fuente: elaboración propia

Los otros componentes del sistema vial son las rutas provinciales y caminos terciarios. Su distribución se relaciona con las actividades y bases económicas a nivel regional, en donde se distinguen actividades turísticas y comerciales (Bracamonte et.al 2013), y aquellas relacionadas con los flujos de movimientos diarios dentro del Área metropolitana Córdoba (Tabla 2). 
Tabla 2. Estructura y función principal de los corredores de la Red de Accesos a Córdoba Capital (RAC) y rutas Nacionales

\begin{tabular}{|l|l|l|}
\hline $\begin{array}{c}\text { FUNCIÓN } \\
\text { PREDOMINANTE }\end{array}$ & \multicolumn{1}{|c|}{ REGIÓN } & \multicolumn{1}{|c|}{ CORREDOR PRINCIPAL } \\
\hline \multirow{5}{*}{ Turística } & Norte (Sierras Chicas) & Ruta Provincial E 53 \\
\cline { 2 - 3 } & Oeste (Valle de Punilla) & $\begin{array}{l}\text { Ruta Nacional N 20/28. } \\
\text { Ruta Provincial E 55 }\end{array}$ \\
\cline { 2 - 3 } & Sur (Valle de Paravachasca-Calamuchita) & Ruta provincial N 5 \\
\hline \multirow{5}{*}{ Comercial } & Norte & Ruta Nacional 9 norte \\
\cline { 2 - 3 } & Este-Litoral & Ruta Nacional N 19 \\
\cline { 2 - 3 } & Rosario-Buenos Aires & $\begin{array}{l}\text { Ruta Nacional N 9 Sur - } \\
\text { Autopista a Rosario }\end{array}$ \\
\cline { 2 - 3 } & Sur & Ruta Nacional N 36 \\
\cline { 2 - 3 } & Corredor bioceánico-MERCOSUR & Ruta Nacional 158 \\
\hline
\end{tabular}

Fuente: elaboración propia en base a Bracamonte et al. (2013)

\section{Consideraciones teóricas y antecedentes}

En el marco de la pandemia, la espacialidad adquirio una relevancia sin precedentes para entender su propagación y distribución, tanto a escala planetaria como local. El mapeo de las enfermedades, es un área de la epidemiología espacial que se preocupa por visualizar y explorar la distribución real de una enfermedad (Franch Pardo et al., 2020), sin embargo en Latinoamérica el campo disciplinar de la geografía o epidemiología de la salud desde análisis espaciales, aún no está consolidado (Fuenzalida \& Cobs, 2013).

Desde el primer trabajo en este campo, realizado por John Snow (1855) que permitio por superposición temática relacionar la epidemia de cólera en Londres con fuentes de agua para consumo contaminada; las tendencias de los análisis espaciales en la geografía de la salud buscan dos objetivos: la exploración de patrones y la búsqueda de relaciones (Openshaw, 1994). El primero se basa en la distancia relativa de ciertas localizaciones respecto de las demás y determina si la distribución es agregada, aleatoria o regular (Upton \& Fingleton, 1985), mientras que el segundo se orienta a identificar cuáles son los determinantes de los patrones y como condicionan su distribución (Rushton, 2003). Ello requiere implícitamente intentar responder tres grandes preguntas; ¿dónde?, ¿cuándo? y ¿por qué?; a partir de la relación entre variables de localización, tiempo y las condiciones contextuales territoriales y de los sujetos (Iñiguez \& Barcellos, 2014). A nivel teórico, implican enfoques hacia la problemática en donde la cartografía cumple funciones diferentes, mientras que uno se orienta a comprender el proceso salud-enfermedad en el espacio geográfico por medio de representaciones 
cartográficas, en el otro la cartografía constituye sólo una herramienta de representación visual de carácter meramente descriptivo (Martinuci, 2019). El abordaje que aquí se presenta se ubica entre ambos. Por un lado, se buscó comprender los condicionantes de la dispersión de la pandemia, bajo el supuesto de que la exposición al contagio se vincula directamente con la movilidad de las personas, tanto a escala intraurbana como entre localidades, a partir de los vínculos funcionales que estas presentan. Por otro lado, se realizaron análisis descriptivos que contribuyeron a determinar su evolución en el espacio - tiempo a diferentes escalas, intraurbana y regional.

Los antecedentes para abordar el análisis espacial de la pandemia de la COVID-19 son numerosos, sin embargo predominan los enfoques regionales basados en análisis de focos de calor (estimación de densidad del Núcleo-Kernel), clústers y autocorrelación espacial en función de las limitaciones de los datos disponibles y su agregación espacial. En Argentina, las investigaciones aplicadas a escala nacional, provincial y de localidades se alimentan de datos de agregación zonal cuya escala mínima es a nivel de localidad (Gomes, 2021; Ramirez, 2020; La Macchia et al., 2020).

Los autores Franch Pardo et al (2020) analizaron 63 artículos científicos sobre análisis geoespacial de la pandemia publicados durante el 2020, e identificaron cinco grupos generales en base a los temas desarrollados, y metodologías: análisis espacio-temporal regional, geografía médica (recursos de salud y vulnerabilidad), variables ambientales, minería de datos y por último en el quinto grupo, mapeo basado en la web, que ha sido ampliamente utilizado para difusión de información al público. Otro enfoque de relevancia, pero de menor alcance en cuanto a antecedentes de aplicación debido a la falta de acceso a datos a nivel de individuo, consiste en el análisis de las redes de movilidad como estructurantes de la propagación del virus. Autores como Perles Rosello et al. (2020, 2021); Romero jiménez et al. (2020); Chinazzi et al. (2020) han realizado estudios en torno a este tema a escala local e internacional.

Cabe referir en este apartado las dimensiones que atraviesan el proceso de construcción cartográfica y sus implicancias en el tratamiento de la problemática concreta. En cuanto a las variables utilizadas y su agregación espacial, es frecuente trabajar con tasas que vinculan la variable de interés respecto de la población total, en función de una unidad de agregación zonal para obtener generalizaciones del fenómeno bajo análisis. Ello requiere intentar minimizar los sesgos referidos a la representatividad de las zonas en las cuales se divide el territorio y su fiabilidad estadística, ya que al definir una unidad de agregación nos enfrentamos al problema 
de la unidad de área modificable, causado por la imposición de unidades artificiales de definición espacial en fenómenos geográficos continuos (Openshaw, 1984), lo que acarrea como consecuencia la generación de patrones artificiales. Cualquier esquema de agregación que se defina implica una uniformidad dentro de las zonas, pero un fuerte contraste entre ellas, y al cambiar sus límites, el análisis puede conducir a resultados significativamente diferentes (Cromley \& McLafferty, 2011; Heywood, 1998). Respecto de las tasas, los sesgos se vinculan a los errores o variaciones locales en la calidad de los datos de salud (numerador) y de población (denominador) que se magnifican en escalas espaciales pequeñas (Ellliot \& Wartenberg, 2004). En el extremo contrario, el uso de escalas espaciales grandes, da valores estadísticamente más fiables pero oculta las variaciones que se producen dentro de las propias unidades (Nakaya, 2000).

En base a ello, y entendiendo que en la generación de cartografía todo recorte implica sacrificar alguna información para poder destacar otra a partir de un proceso de geoconceptualización, mediante el cual se transforma el mundo real en componentes geográficos (Calvo Melero \& Palanques Salmerón, 2017), se decidio trabajar con valores absolutos o proporciones relativas. Esto obedece a dos motivos, el primero responde a la mirada hacia el objeto de estudio y el segundo se vincula a la calidad de los datos.

Respecto al abordaje del objeto de estudio, no se buscó una generalización, ya que ese tipo de información epidemiológica estaba siendo generada desde el Gobierno, sino a poder brindar una mirada hacia lo particular con un anclaje desde lo local a lo regional respetando en términos espaciales la distribución real de la enfermedad. Se buscó identificar y delimitar las variaciones locales y como las mismas incidían en la propagación territorial del virus. En ese sentido Santos plantea que la categoría de análisis dentro de las ciencias sociales no es el territorio, sino el territorio usado, "ya que no son las cosas; sino las cosas, hombres y relaciones lo que lo constituyen". En realidad lo que existe es "relación social, sociedad en cuanto territorio, sociedad en cuanto espacio" (Santos, 1999, p. 18). Esta perspectiva de análisis relacional implica que el territorio, es condicionante no solo en su estructura territorial de significación física, dimensional y contenedora de recursos, sino que es condicionante como contenido en las relaciones sociales que posibilita o restringe.

En relación a la calidad de los datos, se identificaron dos problemas: la infra medición de casos detectados y la falta de datos censales actualizados. Esto último se debe a que el censo de 
población más reciente fue realizado en el año 2010, y las proyecciones de población para las localidades del interior presentan sesgos importantes por migraciones interurbanas.

Desde estas consideraciones, se planteó un análisis espacial intraurbano y regional, dependiente del comportamiento de la enfermedad en el tiempo, que permitió comprender la dinámica territorial de la COVID-19 y arribar a insumos orientados a la toma de decisiones para contener su propagación con un anclaje desde la geografía aplicada. En este sentido, Johnston et al. la define como "la aplicación del conocimiento y habilidades geográficas para la solución o resolución de problemas dentro de la sociedad" (Johnston et al., 2000, p. 30).

El vaivén entre escalas de análisis, datos y representaciones cartográficas permitió adecuar el resultado a las demandas que fueron surgiendo, y a los cambios en el comportamiento de la enfermedad. Desde una escala pequeña, en primer lugar se observan dinámicas internas que tienen que ver con las actividades propias de cada localidad, sectores comerciales, industriales, lugares de encuentro, recreación, entre otros; que inciden en la exposición al virus y posibilidades de contagio. Si nos alejamos, se observan esos vínculos, pero ya en una red de relaciones entre localidades de distinto tamaño y función regional, su articulación con la red vial, la movilidad interurbana y su jerarquía regional. Asimismo, y bajo una mirada regional, veríamos que hay grandes diferencias vinculadas a las actividades productivas características de cada zona de la provincia que inciden en la estacionalidad de la circulación y movilidad. Hacia el oeste del territorio, sobre las sierras las actividades turísticas, con fuerte dinamismo en los meses de verano y con lógicas diferenciadas en función del tipo de turismo de cada microrregión. El sector sur y sureste de la provincia, con predominio de actividades agrícolas ganaderas y dinámicas estacionales vinculadas al campo. Además, los corredores viales articuladores de las relaciones entre provincias en el contexto nacional e internacional. Esta síntesis descriptiva de las dinámicas territoriales es relevante ya que permeo en las decisiones metodológicas para definir los análisis espaciales en diferentes contextos de movilidad de las personas, en función de las medidas de contención implementadas.

\section{Estrategia metodológica}

\subsection{Dinámica de la pandemia}

En la provincia se registra el primer caso el 6 de marzo de 2020, a fines de este mes 28 localidades presentan personas infectadas, de las cuales el $37 \%$ se ubican en la Capital. En las 27 localidades restantes los casos variaron en un rango de 1 a 8 como máximo (Figura 2). 
Luego de la etapa de ASPO (20 al 31 marzo), se flexibilizan paulatinamente las actividades comerciales, de servicios e industriales permitidas, que incluyo la reapertura de comercios de las áreas centrales con horarios de funcionamiento pautados. El 6 de junio se autorizan las salidas recreativas y actividades deportivas en espacios abiertos. Finalmente el 15 de junio, tras 75 días de aislamiento social, se permitieron las reuniones familiares de hasta 10 personas en coincidencia con un fin de semana extendido, que incluyo la movilidad entre localidades pertenecientes a un mismo departamento.

El primer brote de la COVID-19 se registró en los primeros días del mes de abril en un geriátrico (residencia de adultos mayores) ubicado en la localidad de Saldán perteneciente al Área Metropolitana de Córdoba, con 65 personas contagiadas. De ese total, 21 pacientes fueron trasladados a un establecimiento de salud de Córdoba Capital, en donde ocurre un nuevo brote en los primeros días del mes de mayo, que finalizó con un total de 113 contagios en Córdoba capital y localidades del interior.

El 19 de mayo, se detectó un nuevo caso en el área central y comercial de venta mayorista de la ciudad de Córdoba, vinculado al brote anterior, que derivo en 53 personas contagiadas con una concentración en el área central y noreste de la capital.

El incremento de la movilidad y contacto entre personas se evidencia en el mes de julio, con un aumento tanto en la cantidad de casos diarios como en su expansión territorial al interior de la capital y en las localidades del interior, con brotes de picos de casos en localidades de mayor jerarquía urbana y el inicio de la circulación comunitaria del virus. (Figura 2). Tras un incremento sostenido en los casos detectados y número de localidades afectadas, en el mes de octubre ocurre el primer pico de la pandemia. El día en que se registró el máximo de casos para la Capital fue el 8 de Octubre con 1143 personas infectadas, mientras que en el interior, ocurrió el día 15 con 1348 casos. En el mes de noviembre los casos comienzan a descender (Figura 2).

En base al incremento de casos totales mensuales y su distribución territorial se distinguen tres momentos dentro de la evolución espacio-temporal de la pandemia que fueron abordados a partir de estrategias metodológicas diferenciadas. 
Figura 2. Distribución espacio-temporal

e incremento de casos detectados durante el año 2020
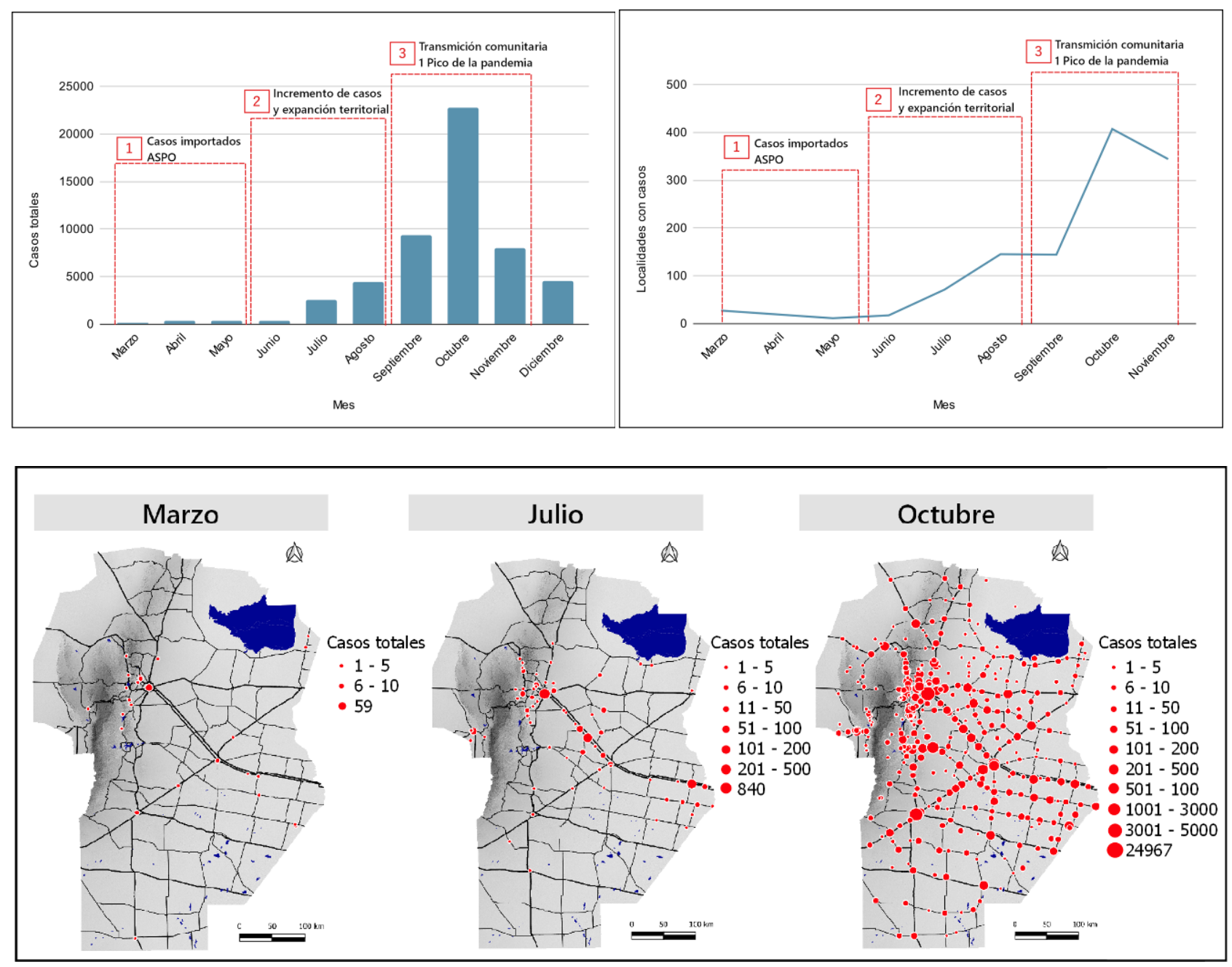

Fuente: elaboración propia

\subsection{Materiales y métodos}

La metodología de trabajo, fue construida a tiempo real en función de la dinámica espaciotemporal de la pandemia, la agregación de los datos de personas con diagnóstico positivo de COVID-19, y las medidas de restricción a la movilidad de las personas. En base a ello se realizaron 3 tipos de análisis espaciales diferenciales (Figura 3).

Los periodos seleccionados representan diferentes momentos de la evolución epidémica y de su distribución espacio- temporal dentro de un contexto factores territoriales internos, estructurales de cada unidad territorial, y externos en su interrelación con los flujos y vínculos entre localidades según su jerarquía urbana regional y nacional. 
El procesamiento de datos, análisis y generación de cartografía se realizó a partir de los programas de código abierto Q gis 3.14, Saga Gis, GeoDa y Google maps. Las fuentes de datos de población con diagnóstico de COVID-19 positivo fueron aportadas por el Ministerio de Salud de la Provincia de Córdoba. Durante el periodo marzo a mayo la localización fue a nivel de individuo y, a partir de junio la agregación de los datos recibidos fue a escala de localidad. Los recortes temporales utilizados en la cartografía para las diferentes etapas variaron entre 5, 10 o 15 días y fueron definidos en conjunto con el Ministerio de salud de la provincia en función del tiempo de duplicación de casos, el valor del RO y; el contexto de transmisión: casos importados, contactos estrechos o circulación comunitaria.

Esta información fue complementada con datos de variables contextuales territoriales propias y obtenidas de diversos ámbitos de gestión, que incluyeron entre otras dimensiones: medidas de contención implementadas, vulnerabilidad social, asentamientos informales, geriátricos, sistema de salud, áreas comerciales, flujo vial, entre otras. En alguno casos se realizaron bases propias a partir interpretación y digitalización manual de imágenes satelitales de alta resolución de Google earth, Max Technology del año 2020.

\section{Figura 3. Metodologías aplicadas}

\begin{tabular}{|c|c|c|}
\hline Contexto & & Análisis espacial y resultados \\
\hline $\begin{array}{l}\text { Aislamiento social obligatorio } \\
\text { Movilidad restringida a } \\
\text { comercios de proximidad }\end{array}$ & $\begin{array}{c}\text { Periodo I } \\
\text { Marzo a Mayo }\end{array}$ & $\begin{array}{l}\text { Áreas de movilidad peatonal supuesta } \\
\text { de personas infectadas -Zonificación } \\
\text { según concurrencia de recorridos - } \\
\text { Áreas de riesgo de exposición al virus }\end{array}$ \\
\hline Flexibilización parcial & $\begin{array}{l}\text { Periodo II } \\
\text { Junio a } \\
\text { Agosto }\end{array}$ & $\begin{array}{l}\text { Autocorrelacion espacial - Índice de } \\
\text { Morans local - Clusters de alta } \\
\text { concentración de casos }\end{array}$ \\
\hline $\begin{array}{l}\text { Flexibilización ampliada } \\
\text { Primer pico de la pandemia }\end{array}$ & $\begin{array}{l}\text { Periodo III } \\
\text { Septiembre- } \\
\text { Noviembre }\end{array}$ & $\begin{array}{c}\text { Recurrencia de casos por periodos de } \\
\text { tiempo e incremento de casos por zona } \\
\text { y localidades - Zonas de circulación } \\
\text { comunitaria del virus }\end{array}$ \\
\hline
\end{tabular}

Fuente: elaboración propia

En el periodo I se realizó un análisis de concurrencia espacial de movilidad peatonal de personas con diagnóstico de COVID-19 positivo, basado en la propuesta metodológica de Perles Rosello et al. (2020) para la ciudad de Málaga España, que establece un análisis de riesgo de contagio en relación a la yuxtaposición del tránsito peatonal de personas infectadas. Bajo este supuesto, adaptado a las condiciones locales y en un contexto de medidas de aislamiento social obligatorio, se partio de la hipótesis que los posibles contagios a futuro se producirían en áreas 
comerciales de proximidad en relación con los posibles recorridos a pie que realizaran las personas infectadas.

Se realizó un análisis de redes de movilidad peatonal según la red vial de cada persona infectada, a partir de distancias fijas establecidas en función a la lejanía promedio de las áreas comerciales de proximidad. Para los barrios de Córdoba Capital y localidades de mayor jerarquía urbana se utilizaron 1000 m, y en las localidades del interior de baja jerarquía 1500 o $2000 \mathrm{~m}$. Las redes de movilidad establecidas se transformaron a áreas, que luego por intersección, permitieron establecer zonas de concurrencia de tránsito posibles, según la cantidad de personas con diagnóstico de COVID-19.

La diferencia de distancias utilizadas se debe a que en la capital, a excepción de algunos barrios exclusivamente de uso de suelo residencial, la mayoría presentan usos mixtos comercialresidencial. Allí los comercios se emplazan en torno a las principales calles que lo vinculan con el área central (Figura 4). Esta configuración se repite en el caso de localidades de jerarquía urbana regional, en contraposición las localidades del interior de menor jerarquía, la zona comercial se encuentra restringida al centro histórico.

\section{Figura 4. Barrios y comercios en Córdoba capital}

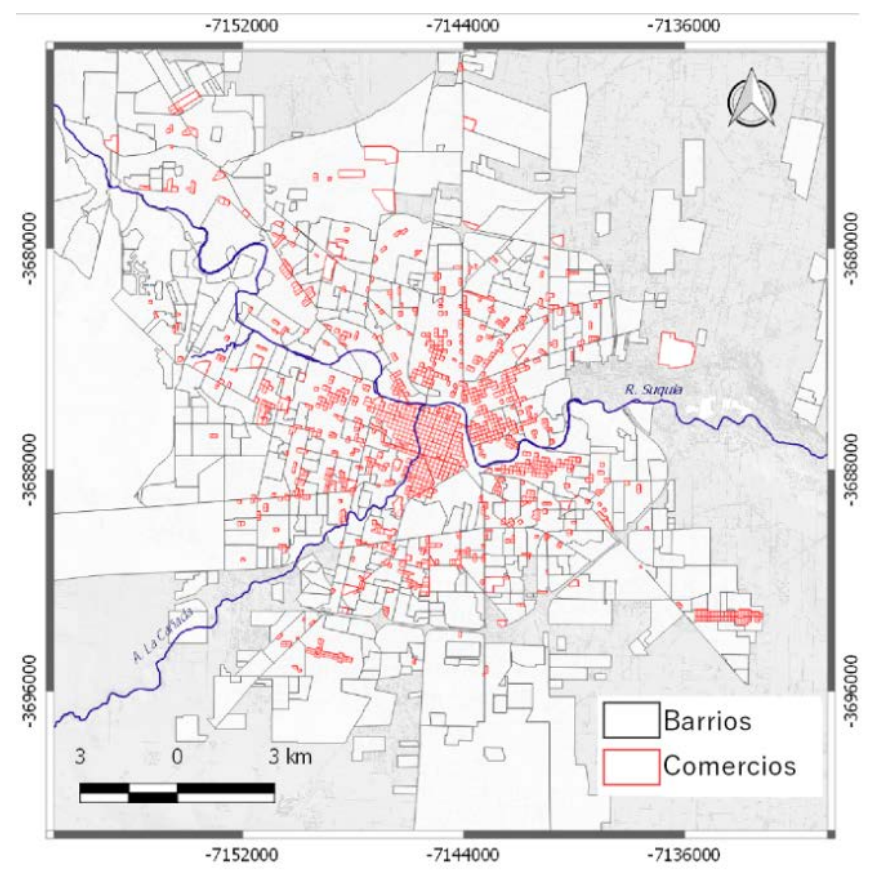

Fuente: elaboración propia

Ante la ausencia de bases de datos georreferenciadas de establecimientos comerciales y de servicios se generaron bases propias para la capital y localidades del interior, mediante las 
localizaciones extraídas de Google maps de las actividades comerciales permitidas: panaderías, verdulerías, carnicerías, almacenes, supermercados, ferreterías, bancos y farmacias.

En el periodo II se trabajó a escala intraurbana mediante análisis de autocorrelación espacial (AE) para determinar la existencia de clústers con alta concentración de casos positivos. Es decir, zonas donde se agrupan casos positivos por encima de lo esperado, asumiendo una hipótesis inicial de distribución aleatoria. Para ello se utilizó el Índice de Morans Local; que determina si el valor que toma una variable, está relacionada o no con los valores que toma en los vecinos colindantes a partir del coeficiente de correlación de Pearson. Se utilizó el indicador local de autocorrelación espacial (LISA) (Anselin, 1995) que descompone el índice I de Moran y verifica en cuanto contribuye cada unidad espacial a la formación del valor general, permitiendo obtener un valor de significancia para cada clúster formado por los valores similares de cada unidad espacial y sus vecinos. (Chasco Yrigoyen, 2006). En este agrupamiento la suma de las unidades espaciales locales es igual al valor global y permite observar como cada unidad espacial se diferencia de sus unidades espaciales vecinas (Buzai \& Baxendale, 2006; Siabato \& Guzman 2019).

La fórmula local estandarizada para I de Moran para la observación i es la siguiente:

$$
I_{i}=\left(Z_{i} / m_{2}\right) \sum_{j=1}^{n} W_{i j} Z_{j}
$$

Donde $\mathrm{m}_{2}$ es la varianza y las observaciones z son las desviaciones de la media. Para los análisis realizados la matriz de pesos elegida fue reina.

Los resultados cartográficos que se obtuvieron bajo esta metodología permitieron establecer las zonas en donde se producía una concentración estadísticamente significativa de valores altos y bajos de los casos COVID-19 detectados.

En este periodo a nivel interurbano se realizaron análisis de dispersión territorial en relación a la red vial y jerarquía urbana vinculada a los brotes de casos, y su dispersión en las localidades vecinas. Para ello se utilizó la jerarquía urbana de las localidades de la provincia a partir de índice de centralidad urbana generado por la subsecretaria de planificación territorial de la Nación, que cuantifica los servicios directos e indirectos que prestan todas las localidades del país con una población superior a los 2000 habitantes, a partir de las variables e indicadores descriptos en la Tabla 3. 
Tabla 3. Índice de centralidad urbana variables e indicadores utilizados

\begin{tabular}{|c|c|c|}
\hline Variable & Descripción & Indicador \\
\hline $\begin{array}{l}\text { Infraestructura } \\
\text { de servicios }\end{array}$ & $\begin{array}{l}\text { Disponibilidad de } \\
\text { infraestructura para la atención } \\
\text { de servicios primarios } \\
\text { (educación y salud) }\end{array}$ & $\begin{array}{l}\text { - Cantidad de camas públicas y } \\
\text { privadas } \\
\text { - Cantidad de instituciones terciarias y } \\
\text { universitarias, públicas o privadas }\end{array}$ \\
\hline $\begin{array}{l}\text { Transporte y } \\
\text { comunicaciones }\end{array}$ & $\begin{array}{l}\text { Grado de equipamiento en } \\
\text { transporte y comunicaciones }\end{array}$ & $\begin{array}{l}\text { - Cantidad de movimiento aéreo, } \\
\text { despegues y aterrizajes de vuelos } \\
\text { comerciales (regulares y no regulares) } \\
\text { x Índice de Accesos Viales }\end{array}$ \\
\hline $\begin{array}{l}\text { Actividades } \\
\text { financieras y } \\
\text { comerciales }\end{array}$ & $\begin{array}{l}\text { Intensidad con que se } \\
\text { desarrolla la economía urbana }\end{array}$ & $\begin{array}{l}\text { - Cantidad de instituciones bancarias x } \\
\text { - Cantidad de grandes superficies } \\
\text { comerciales (hipermercados y } \\
\text { shoppings) }\end{array}$ \\
\hline Población & $\begin{array}{l}\text { Indicador aproximado al } \\
\text { desarrollo urbano, } \\
\text { relacionado con el tamaño del } \\
\text { mercado }\end{array}$ & - Cantidad de habitantes \\
\hline $\begin{array}{l}\text { Estructura } \\
\text { ocupacional }\end{array}$ & $\begin{array}{c}\text { Escala de desarrollo del sector } \\
\text { terciario especializado y el } \\
\text { grado de complejidad del } \\
\text { proceso de trabajo }\end{array}$ & $\begin{array}{l}\text { - Población ocupada en el sector } \\
\text { terciario } \\
\text { - Población Económicamente Activa con } \\
\text { calificación ocupacional profesional y } \\
\text { técnica }\end{array}$ \\
\hline \multicolumn{3}{|c|}{ Categorías } \\
\hline \multicolumn{3}{|c|}{$\begin{array}{c}\text { Nodo internacional (1) } \\
\text { Nodos nacionales (2) } \\
\text { Nodos regionales (3) } \\
\text { Nodos subregionales (4) } \\
\text { Nodos microrregionales A (5) } \\
\text { Nodos microrregionales B (6) } \\
\text { Nodos microrregionales C (7) }\end{array}$} \\
\hline
\end{tabular}

Fuente: elaboración propia en base al Plan estratégico territorial de Argentina (PET, 2011)

En rango de este índice se define a partir de la clasificación de los cinco indicadores en siete categorías, según un orden de importancia creciente. Finalmente para cada localidad analizada a nivel nacional, la jerarquía urbana se establece a partir del promedio de la suma simple de cada indicador con siete categorías finales (Tabla 3). 
Para la provincia de córdoba, este índice presenta 4 tipos de centralidad: 1 nodo nacional correspondiente a la capital provincial, 1 Nodo regional, 15 nodos subregionales y 127 nodos microrregionales. Dado que fue creado para un estudio a escala nacional, y ante la ausencia de los datos de partida que permitieran generar un categorización propia, se optó por redefinir dichas categorías de modo tal que permitieran captar los vínculos funcionales reales en el contexto de las actividades y movilidad permitidas, dentro de las cuales las cabeceras departamentales jugaron un papel de importancia ya que allí se radican las sedes judiciales y administrativas tanto nacionales como provinciales. En base a ello los nodos regionales quedaron compuestos por todas las cabeceras departamentales, más las localidades que presentaran categorías 3 o 4 en el índice nacional, mientras que los nodos microrregionales por las categorías 5,6 y 7 .

La delimitación del área de influencia de cada nodo se realizó aplicando la técnica de interpolación Polígonos de Thiessen, los cuales se conforman a partir de encontrar la distancia media euclidiana entre puntos de interés y sus mediatrices. Las intersecciones de estas mediatrices conforman una serie de polígonos en un espacio bidimensional alrededor de los puntos, de manera que el perímetro de los polígonos generados sea equidistante a los puntos vecinos, delimitando así el área de influencia. Este método asume un espacio homogéneo en donde todos los puntos considerados cumplen con las mismas condiciones de conectividad. Para suplir este déficit se readecuaron las zonas delimitadas en base a las barreras geográficas que representa los cordones serranos y se realizaron conectores en las localidades de borde ya que las mismas pueden ser servidas por más de una centralidad (Figura 5).

Por último en el periodo III, la dinámica de la pandemia fue abordada mediante un análisis de recurrencia de detección de casos por localidad, departamento y pedanía. 1 Esta metodología permitió identificar áreas de circulación del virus a través de recurrencia e incremento de aparición de casos bajo un contexto de decisiones políticas orientadas a intensificar los testeos y los controles de circulación entre localidades.

1 La Pedanía es una subdivisión departamental cuyo principal objetivo es el uso con fines catastrales. La provincia se divide en 130 pedanías. 


\section{Figura 5. Jerarquía urbana localidades de la provincia de Córdoba}

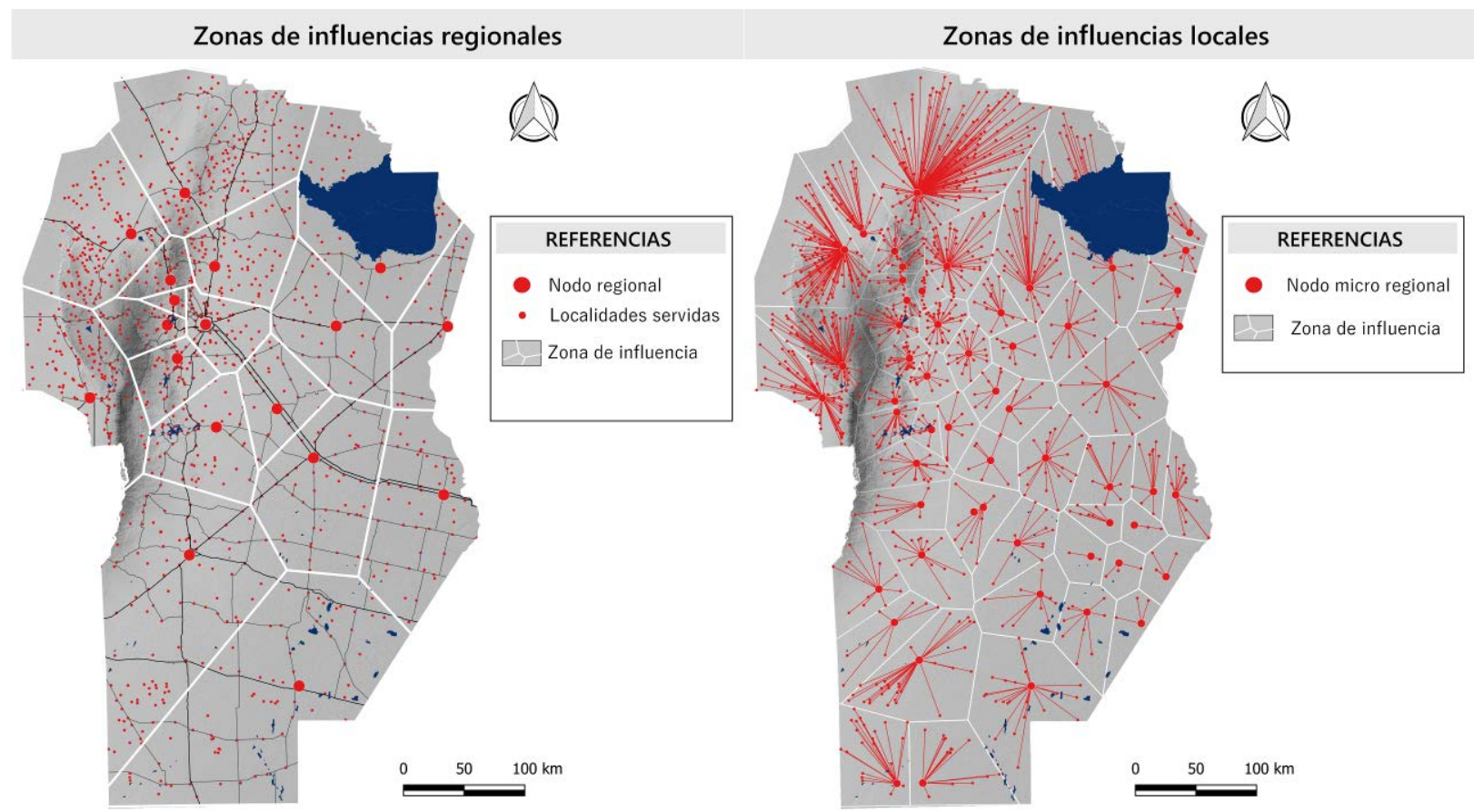

Fuente: elaboración propia en base al Plan estratégico territorial de Argentina (PET, 2011)

\section{Resultados}

Durante el periodo I los análisis espaciales se centraron en la Capital provincial, ya que en ella se desarrolló la mayor expansión territorial de la pandemia.

En cuanto a la detección de casos, inicialmente existió una baja disponibilidad de tests por falta de insumos, sumado a demoras en los resultados. Los análisis de los hisopados para la detección de SARS COV 2 bajo la técnica de amplificación por reacción en cadena de polimerasa (PCR) realizados en todo el país, se procesaban en el Laboratorio del instituto Malbrán provincia de Bs. As., ya que era el único autorizado por la OMS. Recién el 28 de Marzo comienza la descentralización al interior del país. En la provincia de Córdoba, se habilita el laboratorio central provincial dependiente del Ministerio de salud que progresivamente fue ampliando su capacidad diagnóstica hasta alcanzar las 4500 muestras diarias en el mes de Octubre. Además de esta institución, desde el mes de abril se incorporaron nuevos laboratorios, uno con financiamiento público y con capacidad de procesamiento de 450 muestras y, 5 laboratorios moleculares del sector privado en la capital. En cuanto al interior provincial solo existen 3 laboratorios que realizan este análisis. El resto de los institutos privados y públicos que realizan hisopados para PCR derivan las muestras al Laboratorio Central de la Provincia para su análisis. Respecto de los test rápidos de antígenos, ingresan al país en el mes de abril, pero 
recién se masifican en el mes de Septiembre. Las pruebas se realizan en laboratorios privados y en centros de testeos públicos (fijos y móviles), en ambos los casos se notifican diariamente al Sistema Integrado de Información Sanitaria de Argentina (SISA).

Bajo este contexto inicial de falta de tests, los análisis de concurrencia espacial se realizaban de modo diario o semanal con el objetivo de identificar las zonas dentro de los barrios en donde existía mayor posibilidad de exposición al virus, en función de los recorridos peatonales de las personas infectadas. Esto posibilito intensificar los testeos en esos sectores, e identificar nuevos casos, en un contexto en donde se estaba reestructurando el sistema de salud a las nuevas demandas de la pandemia. La estrategia de contención durante este periodo consistio en implementar bloqueos sanitarios en los sectores intraurbanos que presentaran mayor cantidad de casos con impedimento de movilidad de las personas fuera de las áreas establecidas.

En este trimestre las áreas con mayor cantidad de casos COVID-19 se modificaban en función de los primeros brotes registrados durante los meses de abril y principios de mayo. En la Figura 6 se observa, como el patrón territorial de casos detectados se modifica, finalizando en mayo con una concentración en el área central y noreste de la capital.

Figura 6. Evolución de áreas de movilidad en el periodo 1

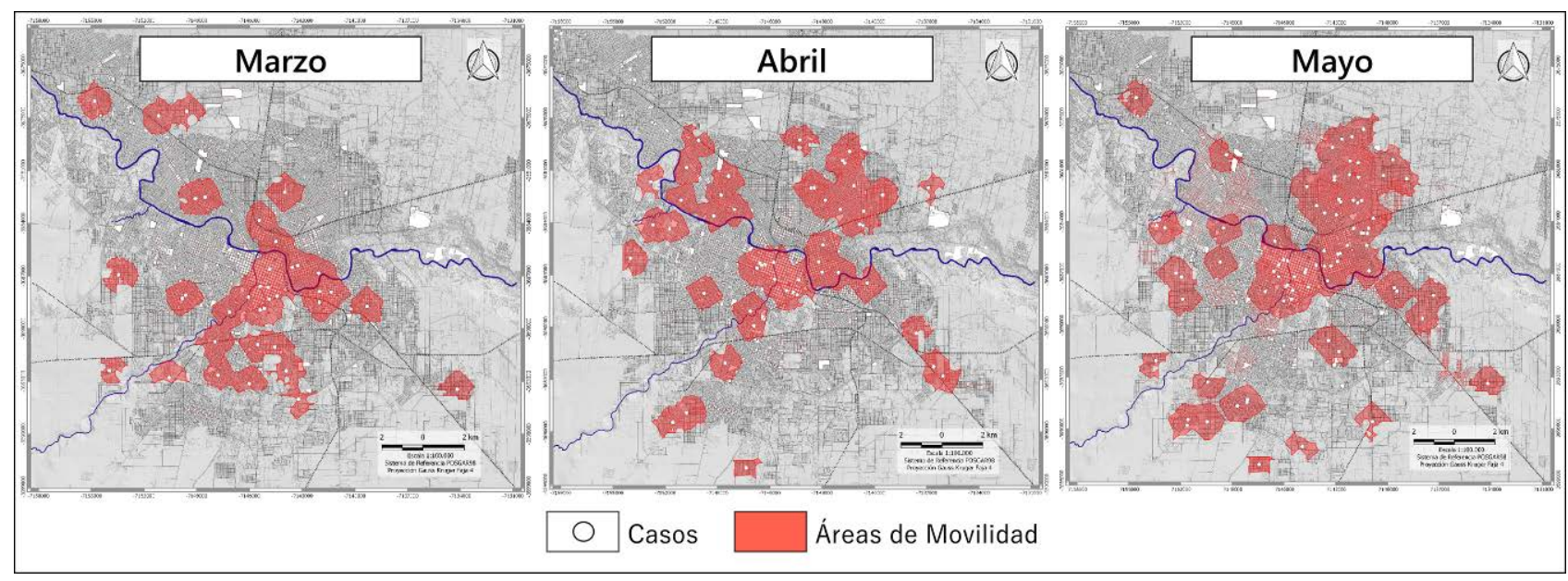

Fuente: elaboración propia

La verificación de la metodología se corroboro a partir de los nuevos casos detectados dentro de las áreas de concurrencia espacial de circulación de personas con diagnóstico positivo de COVID-19 según periodos de 15 días. En la Figura 7 se puede observar un ejemplo correspondiente a la localización de los casos detectados en el periodo 16 al 26 de mayo dentro de las áreas de circulación peatonal de la primera quincena de este mes. El total de casos detectados del 16 al 26 de mayo ascendía a 52, de los cuales 21 correspondían a personas 
contagiadas por ser personal de salud o contacto estrecho con personas infectadas en los 14 días anteriores (información de la base de datos de la investigación epidemiológicas del ministerio de salud de la provincia). De los 31 casos restantes, que aún se encontraban en investigación respecto del nexo epidemiológico, el 13 \% se ubican en áreas de concurrencia 1, el $68 \%$ en áreas de concurrencia 2 a 5 y el $19 \%$ se ubican fuera de las áreas de movilidad establecidas para la primera quincena (Figura 7).

\section{Figura 7. Ejemplo de aplicación de área de concurrencia espacial en el periodo 1 mes mayo}

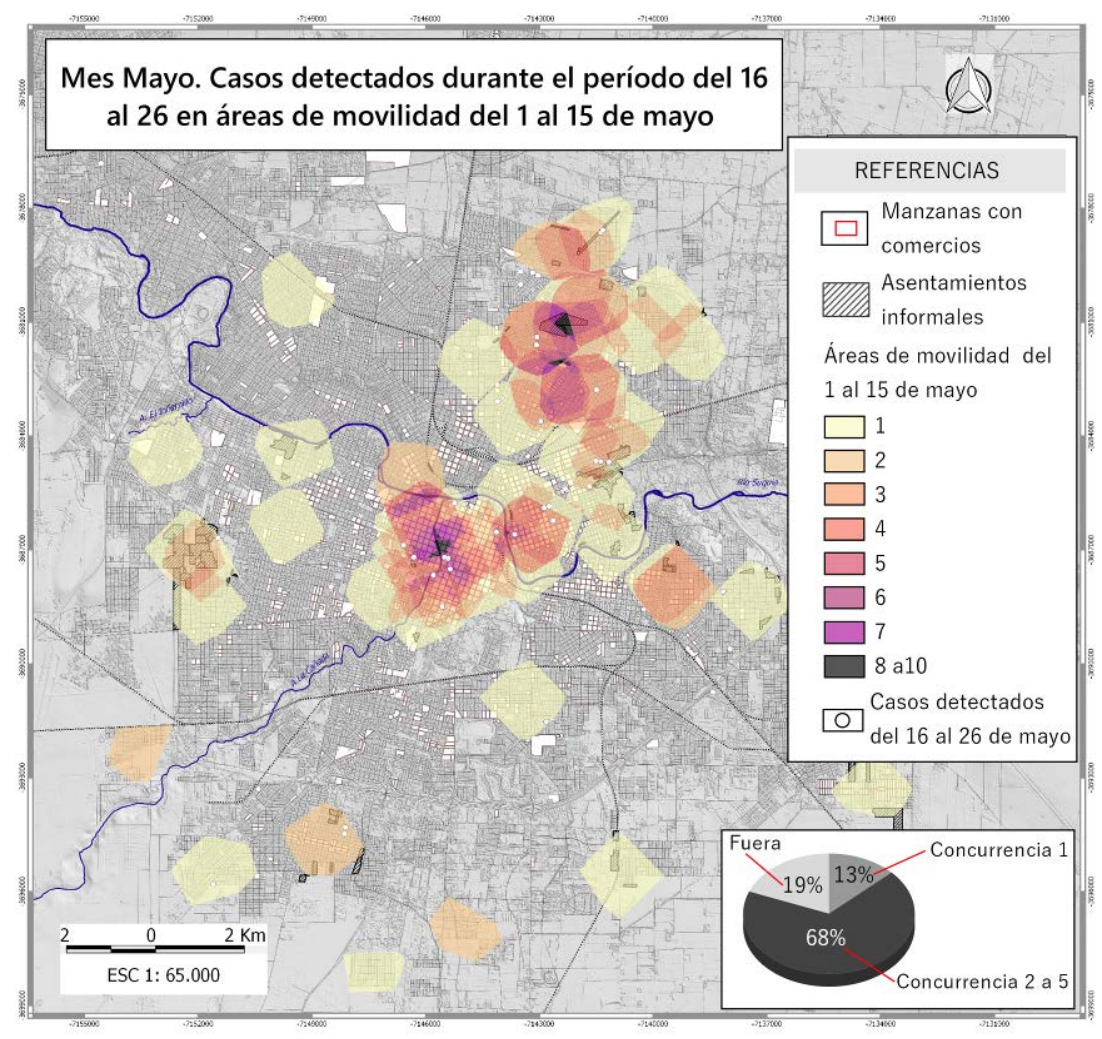

Fuente: elaboración propia

Durante este periodo y los subsiguientes se analizaron también los niveles de contagio en relación a la vulnerabilidad socioterritorial establecida según condiciones de necesidades básicas insatisfechas y asentamientos informales. A nivel nacional los indicadores de necesidades básicas insatisfechas (NBI) se establecen a partir de los censos de población y vivienda con el objetivo de delimitar los grupos sociales que presentan condiciones de pobreza estructural, ya que identifican las dimensiones de privación absoluta de los hogares entendiendo a la pobreza como el resultado de un cúmulo de privaciones materiales esenciales (CNPHYV, 2010). 
Para generar el indicador de vulnerabilidad socioterritorial en relación al contagio de la COVID19, se contempló la población total por radio censal del año 2010 que presentaba los tres indicadores de $\mathrm{NBI}$ asociados a un mayor riesgo: carencias sanitarias (NBI2) comprende los hogares que no poseen retrete; condiciones de hacinamiento ${ }^{2}$ (NBI 3) es la relación entre la cantidad total de miembros del hogar y la cantidad de habitaciones de uso exclusivo, y por último se tuvo en cuenta la capacidad de subsistencia (NB|5), ya que este indicador incluye a los hogares que tienen cuatro o más personas por miembro ocupado y cuyo jefe de hogar no ha completado el tercer grado de escolaridad primaria del sistema educativo nacional.

Este indicador, se complementó con información referida a la ubicación y extensión de los asentamientos informales existentes en la capital y localidades del interior. El mismo fue generado en base a la interpretación de imágenes satelitales y a datos obtenidos de diversas fuentes de organismos nacionales, ONG, municipales y proyectos de investigación de la Facultad de Filosofía y Humanidades (Geografía y Antropología) y Ciencias Sociales-2020: Registro Nacional de Barrios Populares (Renabap, 2016), Barrios Populares ONG Techo (2016). La base cualitativa fue construida por equipos de investigación de la Facultad de Filosofía y Humanidades (Geografía y Antropología) y Facultad de Ciencias Sociales de la Universidad Nacional de Córdoba Argentina-2020 (Figura 8).

Figura 8. Vulnerabilidad socioterritorial y asentamientos informales en áreas de concurrencia espacial
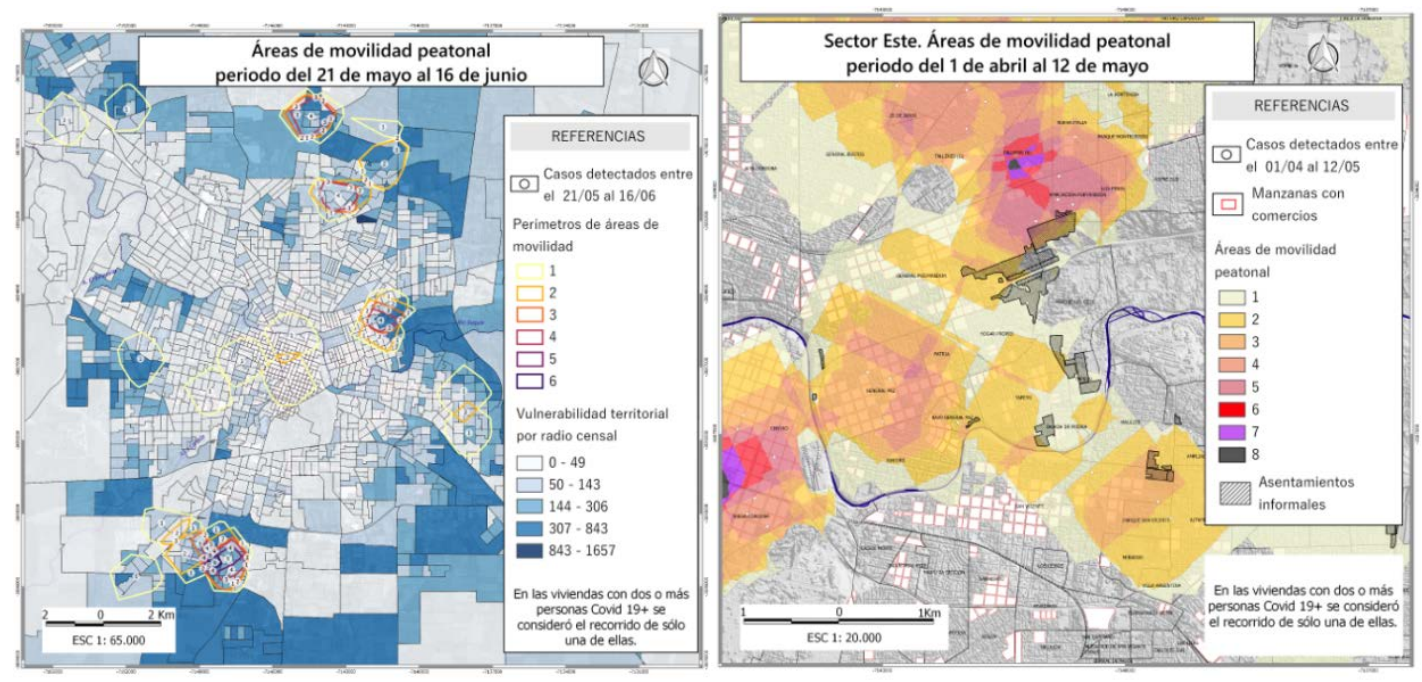

Fuente: elaboración propia

2 Se considera que existe hacinamiento crítico cuando en el hogar hay más de tres personas por cuarto. 
Los resultados que se obtuvieron respecto de la relación entre la vulnerabilidad socioterritorial asociada a una mayor propagación del virus fueron de alcance puntual, ya que si bien en algunos periodos se registró un mayor número de contagios en áreas vulnerables, no fueron casos generalizables. Por otra parte, en los meses de junio, y posteriormente en agosto cuando se autorizan las reuniones sociales, los picos de contagios en la capital se registraron en barrios cerrados de alto poder adquisitivo, y en el interior de la provincia en localidades que no presentaron casos durante el primer periodo. Es decir, los resultados que se obtuvieron demuestran que el nivel de contagios intraurbano se relaciona con las prácticas sociales y de cuidado, más que a las condiciones socioeconómicas.

No obstante, el análisis de vulnerabilidad socioterritorial permitió visibilizar situaciones de pobreza, que frente a la enfermedad no podrían sobrellevar el aislamiento, debido a condiciones de hacinamiento en las viviendas y a necesidades de trabajo diario para sostenimiento de las familias. Este hecho derivo en decisiones políticas respecto a la necesidad de definir espacios físicos para que las personas afectadas transitaran el periodo de aislamiento, en establecimientos preparados para ello, como por ejemplo hoteles o colonias de vacaciones. Asimismo se acompañaron los controles con ayudas materiales (alimentos y productos de higiene) para familias carenciadas.

En el segundo momento, con la apertura parcial de ciertas actividades, aumenta la movilidad y circulación de personas y se expanden los casos a escala urbana en la ciudad de Córdoba, la Figura 9 da cuenta de dicha expansión comparando la primera y segunda quincena de julio, según el área total de los posibles recorridos peatonales de personas infectadas. Bajo este contexto de movilidad ampliada, el análisis de concurrencia espacial se torna ineficiente para captar la dinámica de la pandemia ya que las personas dejaron de moverse en torno a los comercios de proximidad, y cobra relevancia la detección de contactos estrechos a escalas espaciales más amplias. Esta dinámica de la pandemia también se verifica en las localidades de mayor tamaño del interior provincial en los meses de julio y agosto.

Para poder identificar la concentración de casos COVID-19 positivos y la interrelación espacial entre barrios a escala intraurbana, se recurrió a análisis de autocorrelación espacial local mediante la aplicación del Índice de Morans Local. En función de las necesidades requeridas para la toma de decisiones los clusteres identificados se agruparon en dos clases: alto-alto, en donde los barrios con niveles elevados de casos presentaban vecinos con niveles elevados y bajo-alto, es decir zonas de valores elevados rodeados de valores bajos (Figura 10). Esta 
simplificación de los resultados que se obtienen mediante esta metodología en esas dos categorías permitió que se realizaran testeos en las zonas delimitadas como bajo-alto para contener la expansión territorial de la enfermedad.

Figura 9. Expansión de casos en Córdoba capital según quincenas mes julio

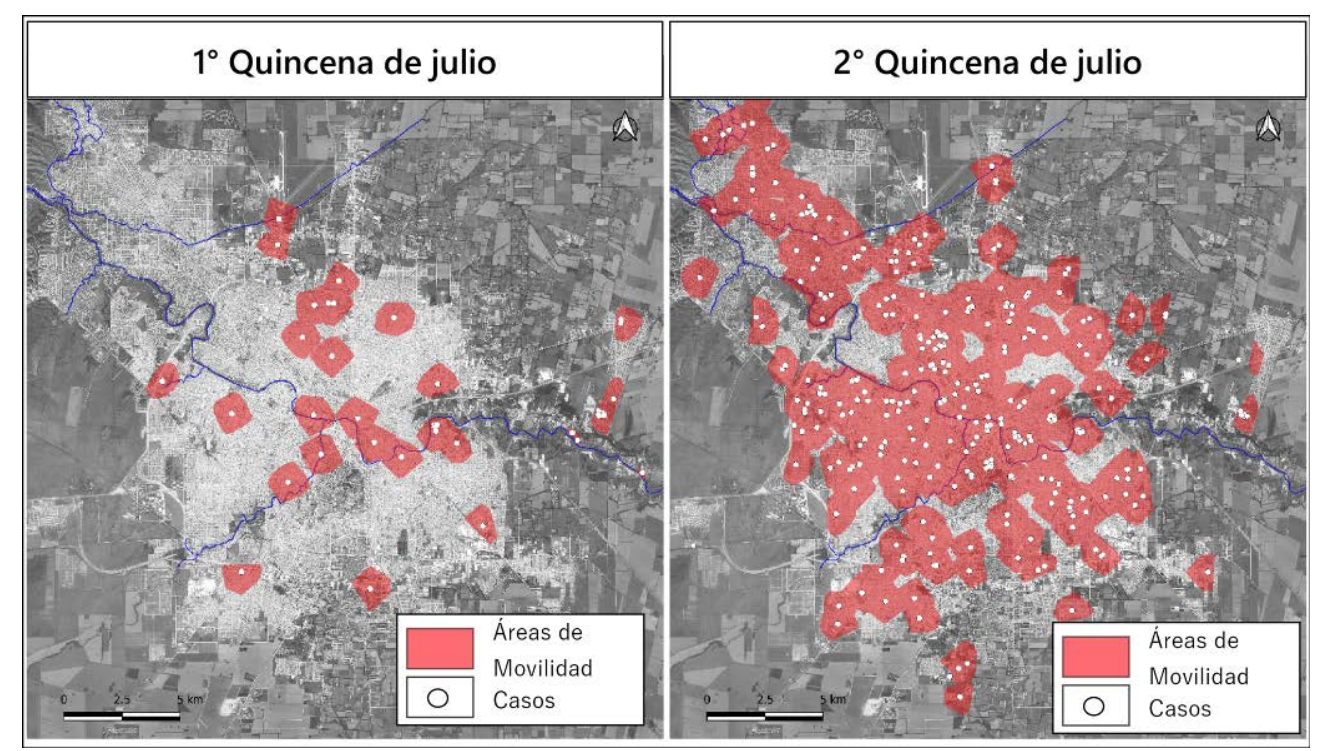

Fuente: elaboración propia

En la Figura 10 se presentan un ejemplo de análisis realizado para la Ciudad de Córdoba. Los resultados obtenidos indican dos zonas relevantes en términos de clusterización de casos de la COVID-19. La primera corresponde al área central--pericentral, y la segunda a los barrios colindantes a Villa el Libertador. Este barrio es uno de los que presenta mayor crecimiento urbano y demográfico de la ciudad de Córdoba, al año 2010 según el censo provincial su población ascendía a 29535 habitantes. Asimismo, la infraestructura, equipamientos y servicios urbanos no alcanzan a cubrir las demandas existentes. Solo el $10 \%$ del barrio posee servicios de cloacas (Buffalo \& Rydzewski, 2016). 


\section{Figura 10. Autocorrelación espacial en la Ciudad de Córdoba}

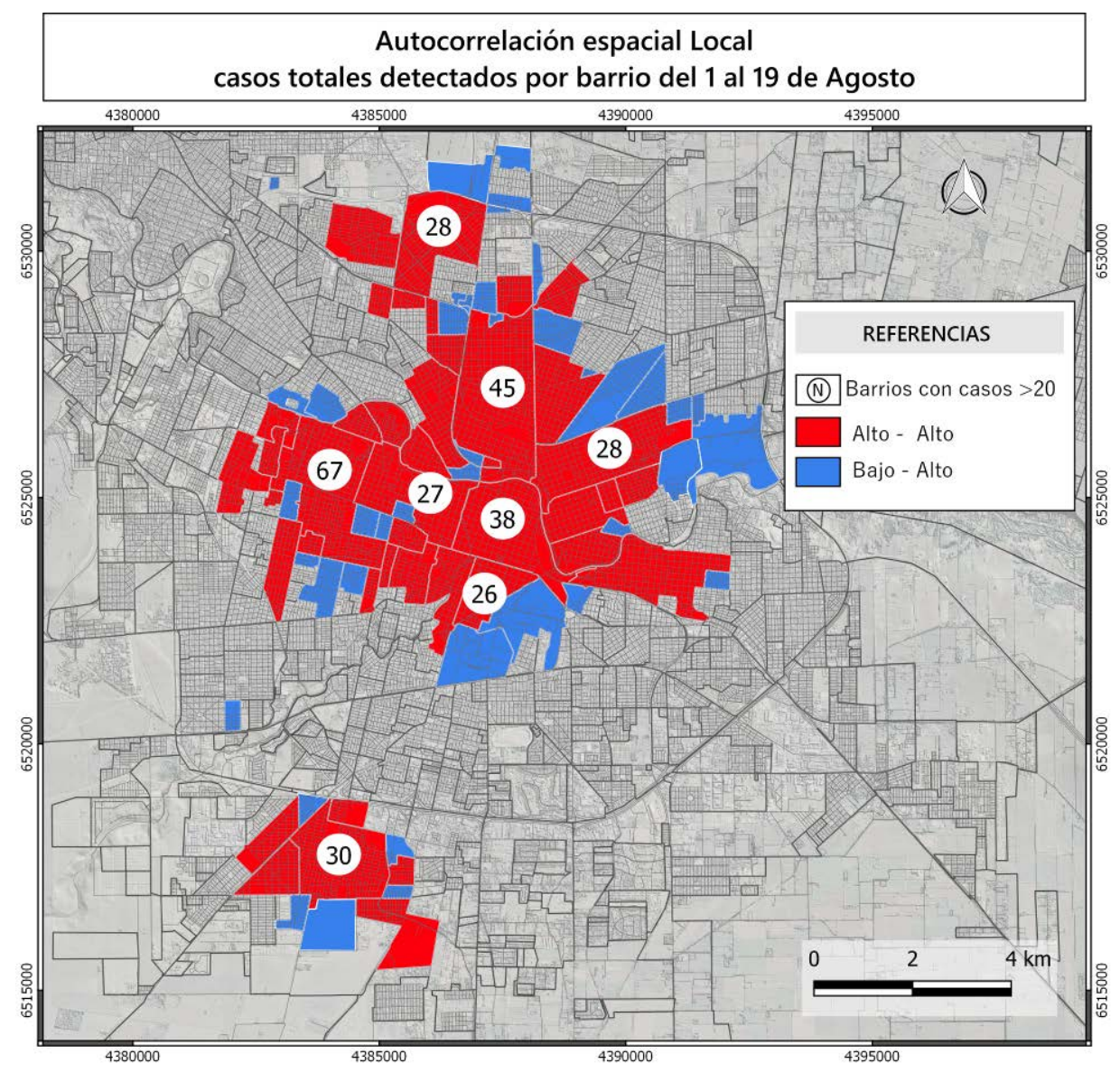

Fuente: elaboración propia

Respecto de las localidades del interior como se puede observar en la Figura 11, se analizó la evolución del contagio entre localidades en relación a la jerarquía urbana y conectividad vial principal en términos de casos totales por periodos de tiempo, y su vinculación según el camino más corto entre localidades con casos. Esto posibilito establecer controles de circulación, ya que ante el bloqueo de localidades por aparición de brotes, los ciudadanos se movilizaban por la red vial terciaria. Asimismo permitió identificar que para este periodo el patrón de dispersión territorial se vinculaba a los corredores viales de mayor circulación de personas y de transporte de cargas de la provincia.

Dada la magnitud de los casos registrados, los análisis intraurbanos se realizaron para Córdoba capital y en aquellas localidades que presentaban brotes. En la Figura 12, se pueden observar los resultados obtenidos para la localidad de los Surgentes, que posee 2795 habitantes y 974 viviendas (CNPHYV, 2010); en ella el primer caso fue detectado el 25 de julio y al mes contabilizaba 223 casos. 


\section{Figura 11. Análisis a escala interurbana}
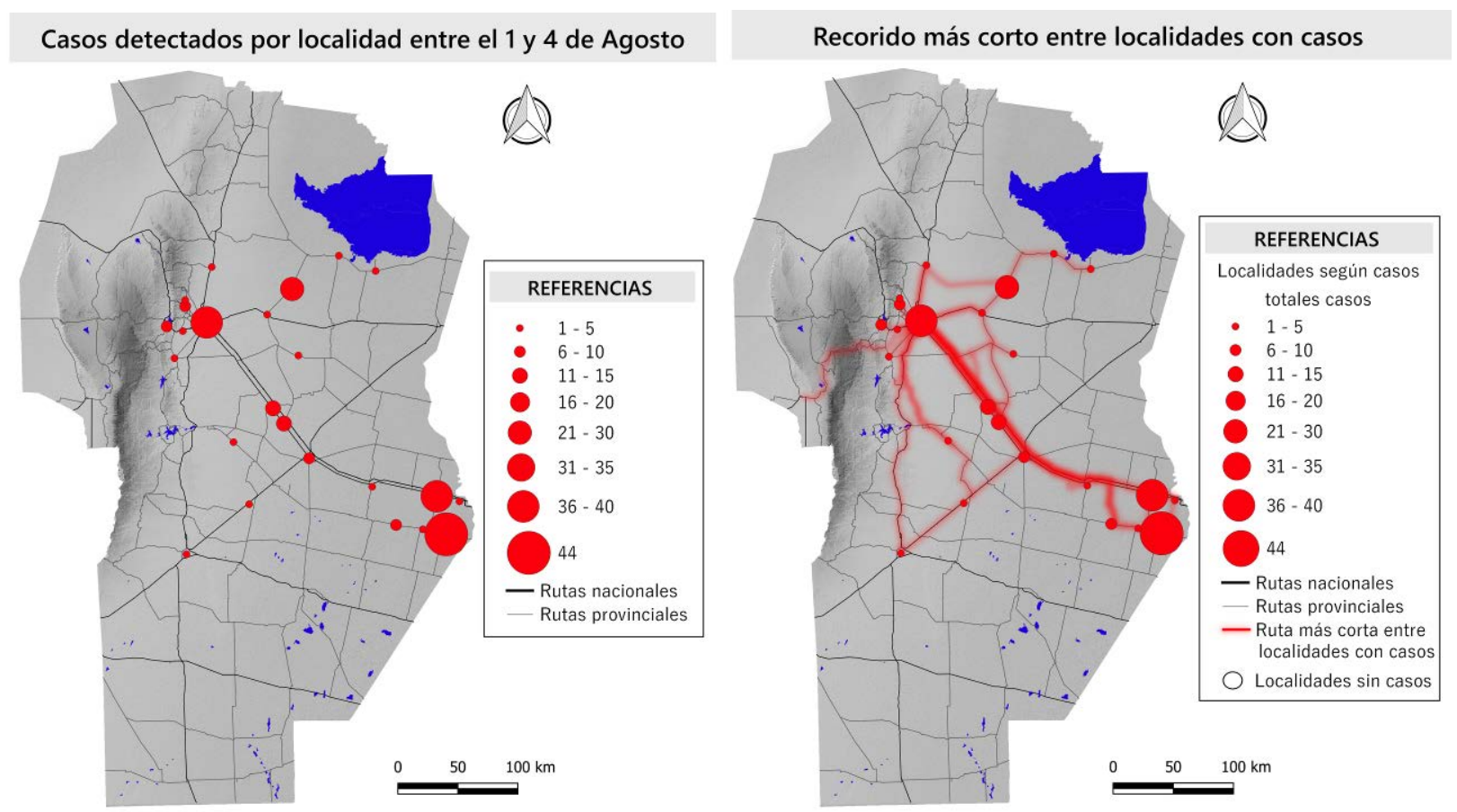

Fuente: elaboración propia

La cartografía realizada indico los casos nuevos detectados según periodos de 5 días, identificando las manzanas en donde se localizaban los mismos. Al final del periodo analizado, solo 24 manzanas no registraron casos de un total de 65.

La evolución del contagio en esta localidad, como se evidencia en la figura 12, se registro en relaciones de proximidad por contactos estrechos, ya que desde el inicio de la pandemia no había registrado casos de transmisión comunitaria. Esto genero una falsa sensación de seguridad y un relajamiento en las prácticas de cuidados, según resultados de la investigación epidemiológica y seguimiento de casos y contactos estrechos, aportados por el Ministerio de salud.

Cuando se autorizan las reuniones sociales en los barrios cerrados ubicados en la capital, ocurrio el mismo fenómeno que en la localidad de los Surgentes. 
Figura 12. Casos detectados cada 5 días en la localidad de Los Surgentes
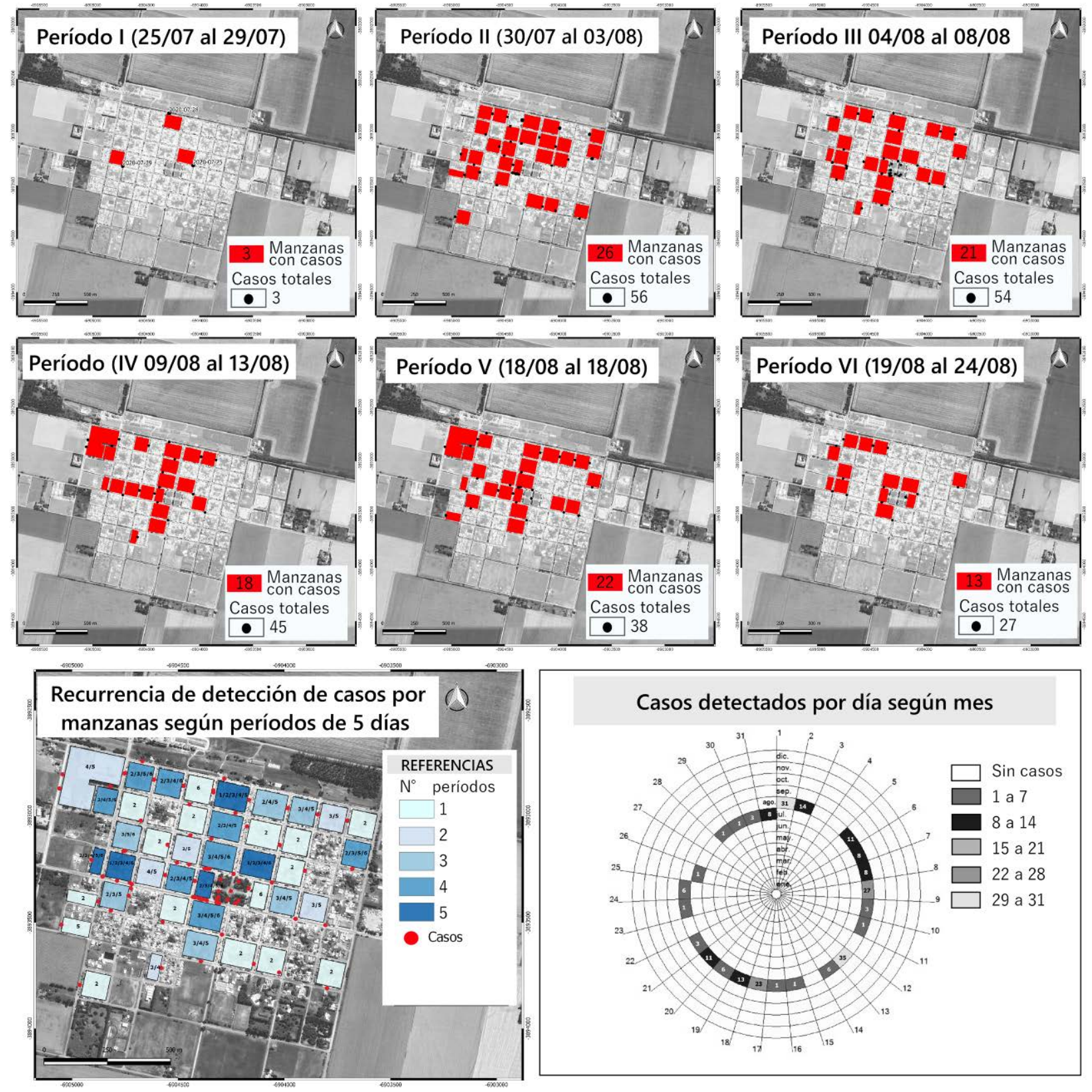

Fuente: elaboración propia

Los barrios cerrados son urbanizaciones residenciales especiales que se desarrollan dentro de un perímetro cerrado, con única vía de acceso y seguridad privada las 24 h, no son de libre circulación y para poder ingresar se debe contar con una autorización de algún residente del barrio o de la administración del lugar. Dentro de sus instalaciones cuentan con áreas de recreación y salones de usos múltiples en donde se suelen realizar eventos sociales. Para su análisis se debió generar una capa propia de urbanizaciones cerradas ya que la existente estaba desactualizada y solo comprendía Córdoba capital, para su identificación y delimitación se utilizaron imágenes satelitales, registro de páginas web especializadas en venta de de lotes y 
viviendas en este tipo de urbanización a nivel provincial. En la Figura 13 se encuentran los resultados obtenidos para Córdoba capital, en donde de los 59 casos registrados en barrios cerrados desde el inicio de la pandemia, 3 correspondían a casos detectados en marzo y mayo con clasificación epidemiológica de 1 caso importado, y a 2 casos de trabajadores de salud. Los 56 casos restantes se vinculaban a contactos estrechos al interior de los barrios identificados entre el 20 de julio y el 12 de agosto. Respecto de los nexos epidemiológicos entre los contagiados manifestaron reuniones sociales o familiares.

Esta breve descripción narra las principales circunstancias de contagio previas al primer pico de la pandemia.

Figura 13. Casos detectados en barrios cerrados desde marzo a agosto de 2020

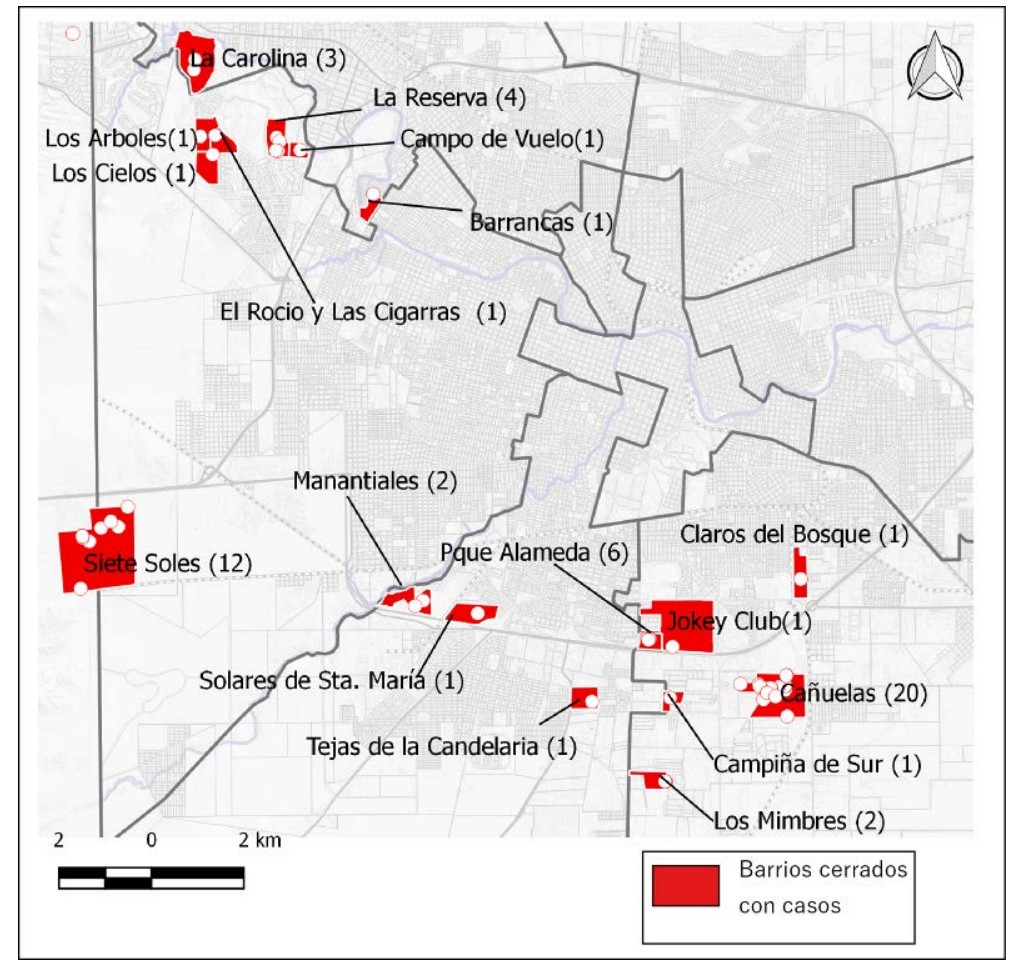

Fuente: elaboración propia

En términos de incidencia de casos a nivel provincial los puntos críticos iniciales se ubicaron en las ciudades de mayor jerarquía urbana, pero una vez iniciado el proceso de circulación comunitaria, las localidades intermedias y pequeñas fueron las que se vieron más gravemente afectadas a partir de brotes. A modo de ejemplo, hasta el 9 de agosto en la localidad de los Surgentes existían 34 casos por cada mil habitantes mientras que en la capital la incidencia era de 1.3. Respecto del resto de las localidades que registraron brotes esta dinámica se replicó, en 
orden descendente se destacan: Oliva con un 27.7; General Roca 17.6; Oncativo 11.3; Marcos Juárez 9.2; Saldán 5 y Villa Dolores 4.1.

El tercer periodo de análisis corresponde al pico de la pandemia. En la Figura 14, se observa el análisis de recurrencia para el mes de octubre según periodos de 5 días por pedanías. Las zonas de color rojo refieren a la detección de casos para los 4 periodos analizados, las naranjas aquellas con 2 o más periodos que incluyeran el último y finalmente el amarillo corresponde solo las localidades con casos registrados en el último periodo de 5 días.

Los resultados obtenidos pretermitieron determinar las zonas a nivel provincial que se encontraban con mayor circulación comunitaria del virus. Esta información contribuyo a la toma de decisiones políticas que se plasmó en controles de circulación e intensificación de testeos.

Por otra parte, en las localidades del interior se realizaron análisis espaciales de movilidad peatonal de los casos detectados en relación a los establecimientos geriátricos, a razón que esta franja etaria presentaba la mayor tasa de mortalidad, y en conjunto con los mayores de 60 años, las mayores demandas de internación parar el sistema hospitalario.

Figura 14. Análisis de recurrencia por pedanías según periodos de 5 días

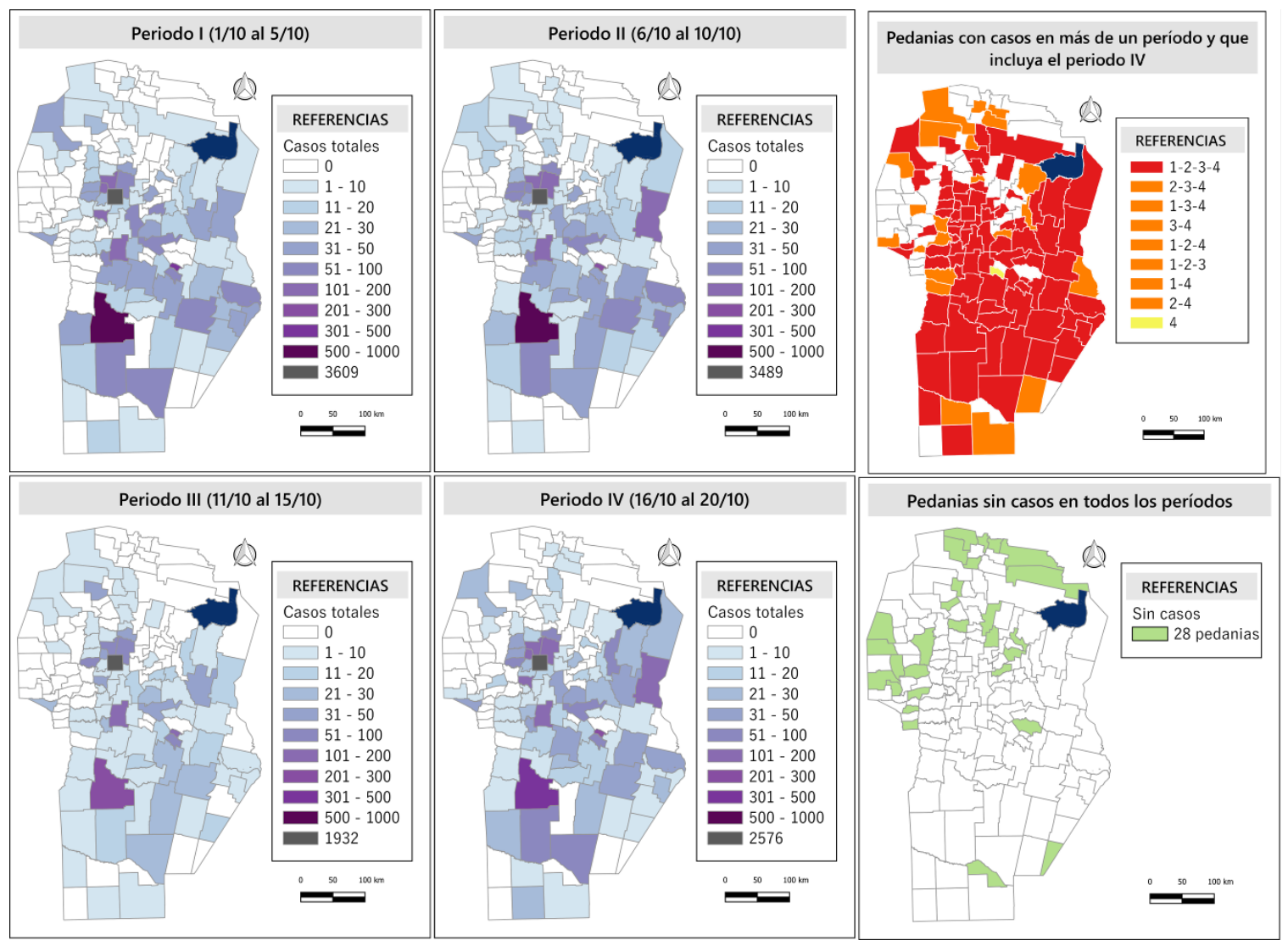

Fuente: elaboración propia 
Desde el mes de marzo en las residencias para adultos mayores (geriátricos), se habían implementado estrictos protocolos de funcionamiento, que incluyeron la prohibición de visitas de familiares o allegados de modo físico. Sólo estaba permitido contacto visual a través de un vidrio y los vínculos sociales se realizaban mediante llamadas de telefónicas. En cuanto a los trabajadores y prestadores de servicios, antes del ingreso a la institución se establecieron zonas de control en donde a cada empleado debía cambiarse la ropa y calzado, se le media la temperatura y tenía que completar una declaración jurada diaria, donde debía manifestar si había presentado síntomas y si se expuso al virus en los últimos quince días. Además de las medidas mencionadas, al interior de los establecimientos se implementaron normas de bioseguridad referidas a protocolos de aseo, desinfección, distanciamiento entre los residentes, aislamientos de casos sospechosos entre otras (COE, 2020).

Pese a ello, el 8 de abril se registra el primer brote en un geriátrico, de los 70 adultos mayores residentes, 50 se contagiaron y 18 fallecieron. Respecto de los 35 trabajadores de este establecimiento, 15 contrajeron el virus. Desde entonces los brotes de casos en geriátricos de la provincia fueron una constante, llegando a un pico de casos en los meses agosto y septiembre con 250 infectados mensuales.

En todos los brotes registrados el caso cero se asoció a trabajadores de estos establecimientos. Esto evidencia condiciones de pluriempleo en el trabajo, y es uno de los factores que favorecen el contagio de este sector, ya que esta condición se presenta tanto en personal médico y trabajadores directos de la salud, como en los prestadores de servicios de salud; quienes realizan su jornada laboral en más de una institución, incrementando el riesgo de exposición al contagio. En base a ello, los análisis realizados se orientaron a determinar la proximidad de casos COVID-19 en establecimientos geriátricos y en relación a los domicilios de los trabajadores.

En la figura 15 se observa un ejemplo de la localidad de Rio Cuarto en este caso el análisis se focalizo en los casos COVID-19 existentes en proximidad de los domicilios de los trabajadores para ello se utilizó un radio de 300 m según la red vial, la lógica de este análisis se basó en los posibles contactos estrechos entre vecinos próximos.

Otro análisis realizado para las localidades del interior se puede observar en la Figura 16, orientado a identificar los casos COVID-19 activos en proximidades de los establecimientos geriátricos, y los comercios de proximidad, entendiendo que en estos sectores la exposición al contagio de los trabajadores podría ser mayor. 
Figura 15. Trabajadores de establecimientos Geriátricos y proximidad a casos COVID-19 detectados

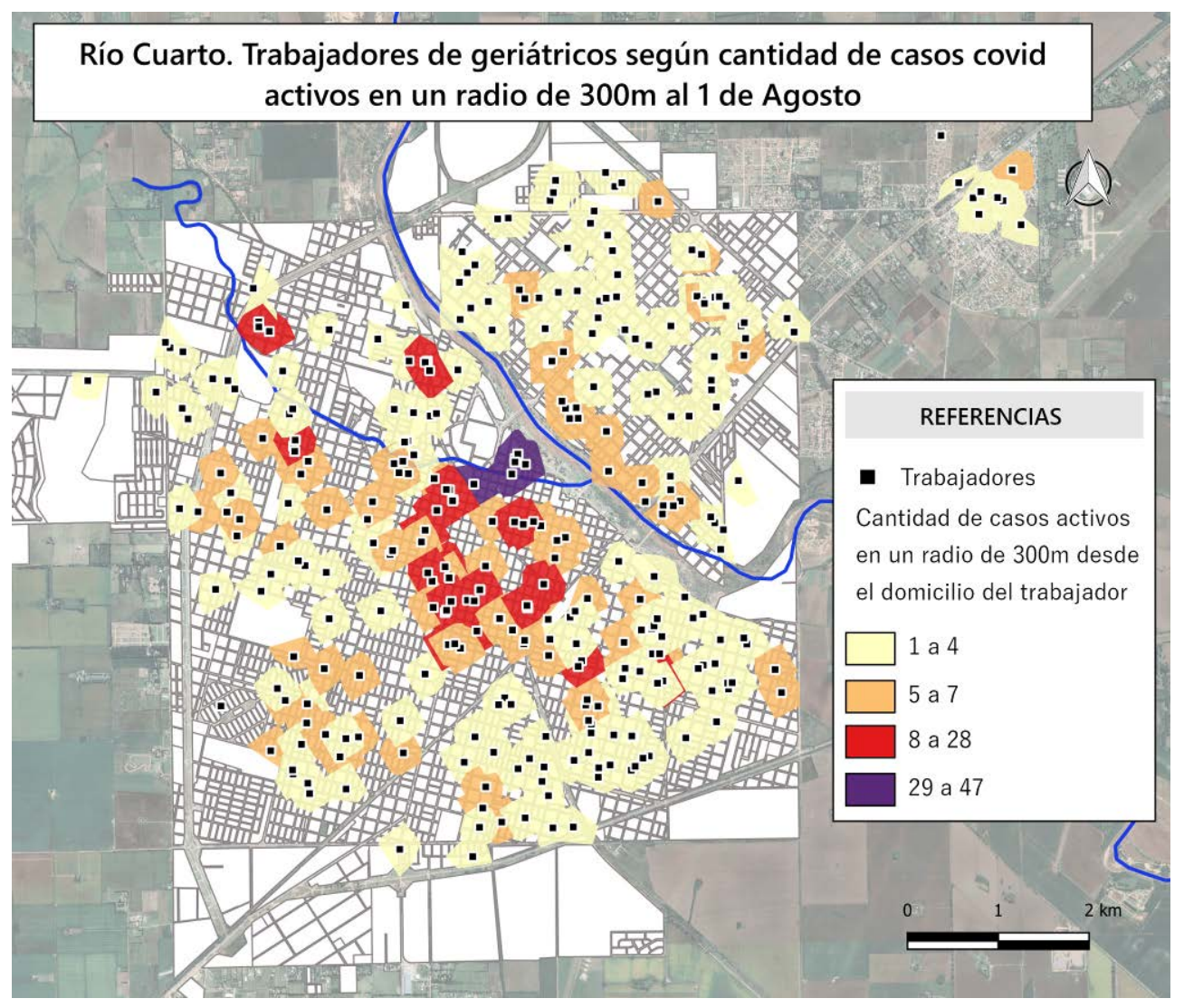

Fuente: elaboración propia

Figura 16. Establecimientos Geriátricos y recorridos peatonales de casos COVID-19 detectados

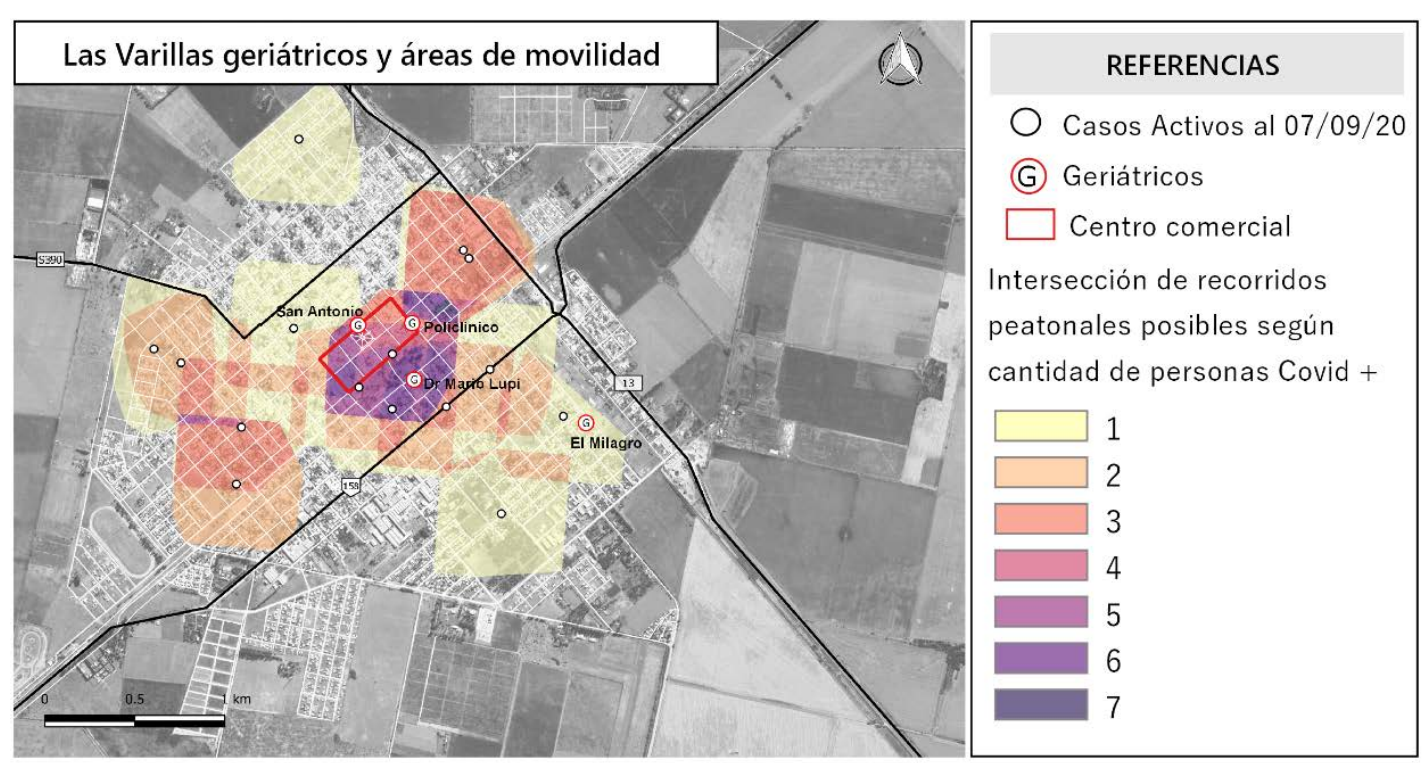

Fuente: elaboración propia 
Otros análisis contextuales realizados, y ante un posible incremento de casos frente a la reapertura de las actividades turísticas, consistieron en determinar las plazas totales de alojamiento disponibles por área turística en relación a las posibles demandas al sistema de salud. Se realizo una base de datos a partir de información aportada por la Agencia Córdoba Turismo (organismo oficial provincial) y por la dirección provincial de estadísticas y censos.

Se realizaron 3 tipos de análisis; el primero consistió en establecer el total de plazas disponibles según tipología segmentadas por área turística (Figura 17). En el segundo se determinó la población total a servir por el sistema de salud de alta complejidad según área turística. Para ello se consideró la proyección de población estable y el incremento esperado en periodo estival, en función de los máximos visitantes recibidos durante las temporadas del periodo (2015-2020) (Figura 18).

La información obtenida contribuyo a la toma de decisiones políticas de incorporación de camas hospitalarias, y la implementación de centros de testeos móviles, que permitieron ampliar la capacidad diagnóstica en las áreas turísticas con mayor número de visitantes.

En el tercero se identificaron, dentro de cada región turística, las localidades que se encontraran a un tiempo de llegada al hospital más cercano, mayor de $30 \mathrm{~m}$. En la cartografía realizada se indicó además cual era el recorrido más corto para arribar al mismo (Figura 19).

Este análisis se vincula a los problemas que se presentaron en relación a la disponibilidad de ambulancias registradas en los brotes ocurridos al interior de localidades pequeñas, en donde desde el mes de septiembre, el sistema de salud no alcanzo a cubrir la demanda en algunas localidades del interior. 
Figura 17. Plazas turísticas totales y por tipo para la temporada 2021 según áreas turística de la Provincia de Córdoba

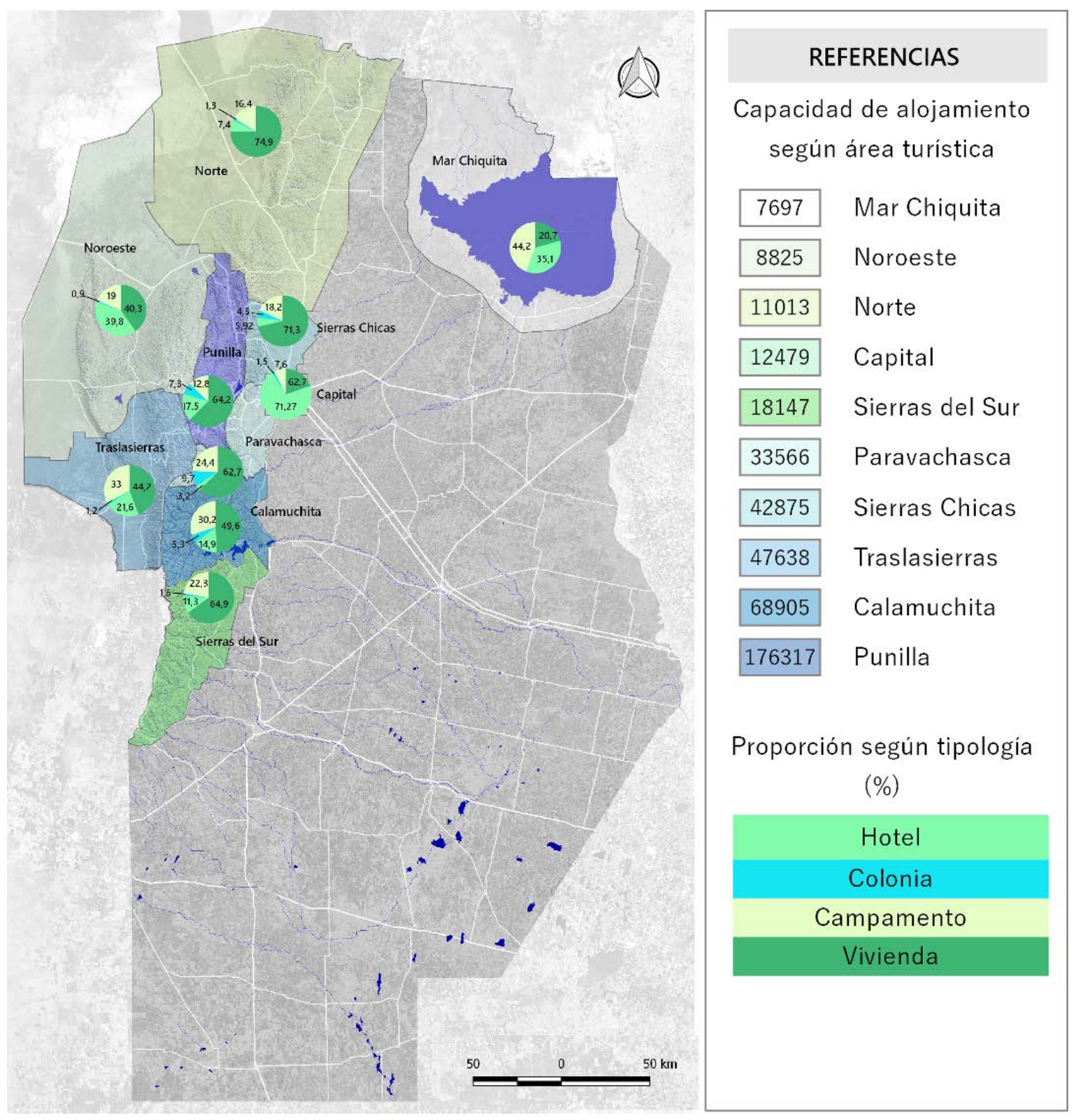

Fuente: elaboración propia a partir de la Agencia Córdoba Turismo (2015) 
Figura 18. Población total estimada para la temporada turística 2021 según área turística y disponibilidad de camas Covid en hospitales de alta complejidad

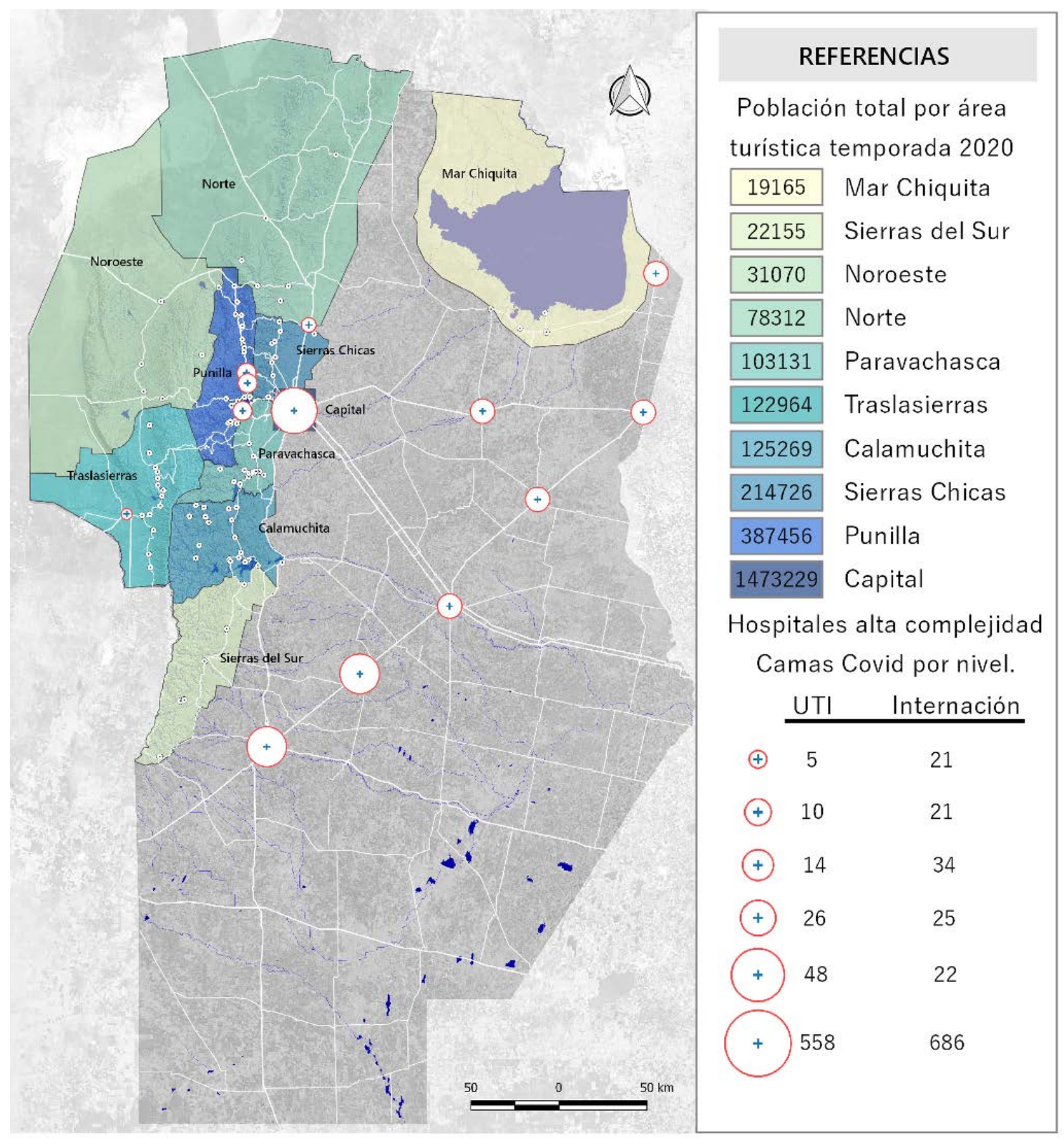

Fuente: elaboración propia a partir de la Agencia Córdoba Turismo (2015) 
Figura 19. Recorrido de localidades hospitales de alta complejidad

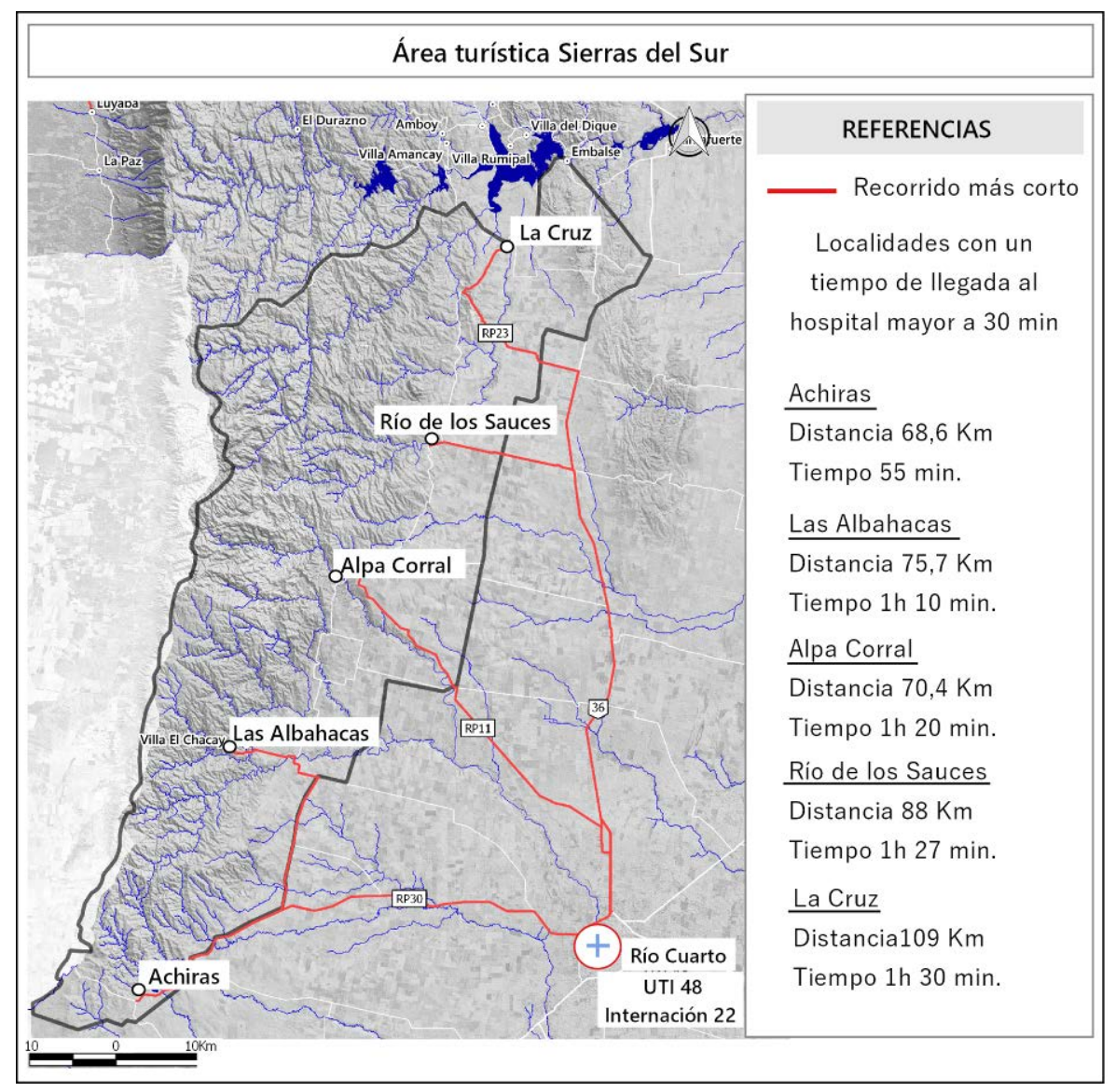

Fuente: elaboración propia

A modo de cierre a nivel provincial y tras atravesar el primer pico de la pandemia, el año 2020 finaliza con una incidencia de casos mayor, que los registrados en la capital provincial, en cuatro departamentos (Tabla 4). Hecho que no puede ser explicado por la cantidad de población o por la cantidad de localidades que los integran, ya que sus valores son similares a departamentos con baja incidencia (Figura 20). 
Tabla 4. Población, localidades, casos acumulados y tasa de incidencia cada 100000 hab para el año 2020 según departamentos de provincia de Córdoba

\begin{tabular}{|l|c|c|c|c|}
\hline \multicolumn{1}{|c|}{ Departamento } & $\begin{array}{c}\text { Población } \\
\text { estimada }\end{array}$ & $\begin{array}{c}\text { Casos } \\
\text { acumulados } \\
\text { año 2020 }\end{array}$ & $\begin{array}{c}\text { Incidencia } \\
\text { cada } \\
100 \text { 000 } \\
\text { hab. }\end{array}$ & $\begin{array}{c}\text { Cantidad } \\
\text { de } \\
\text { localidades } \\
\text { y parajes }\end{array}$ \\
\hline Capital & 1453684 & 59031 & 4060,79 & 1 \\
\hline Colón & 301889 & 7448 & 2467,13 & 73 \\
\hline Río Cuarto & 277775 & 13267 & 4776,17 & 81 \\
\hline San Justo & 228501 & 8046 & 3521,21 & 64 \\
\hline Punilla & 213136 & 3525 & 1653,87 & 56 \\
\hline General San Martín & 144441 & 6055 & 4192,02 & 23 \\
\hline Tercero Arriba & 121541 & 5573 & 4585,28 & 23 \\
\hline Santa María & 119033 & 3283 & 2758,06 & 55 \\
\hline Unión & 117925 & 3240 & 2747,51 & 45 \\
\hline Río Segundo & 116106 & 3654 & 3147,12 & 33 \\
\hline Marcos Juárez & 115019 & 5347 & 4648,8 & 40 \\
\hline Calamuchita & 70512 & 1375 & 1950,02 & 45 \\
\hline Juárez Celman & 69812 & 2199 & 3149,89 & 24 \\
\hline Cruz del Eje & 68656 & 651 & 948,21 & 95 \\
\hline San Javier & 60165 & 986 & 1638,83 & 31 \\
\hline Río Primero & 53832 & 1668 & 3098,53 & 53 \\
\hline San Alberto & 43908 & 459 & 1045,37 & 62 \\
\hline General Roca & 40626 & 894 & 2200,56 & 53 \\
\hline Presidente Roque Sáenz Peña & 40409 & 1198 & 2964,69 & 23 \\
\hline Ischilín & 36276 & 568 & 1565,77 & 55 \\
\hline Totoral & 21686 & 404 & 1862,95 & 45 \\
\hline Río Seco & 15494 & 102 & 658,32 & 49 \\
\hline Tulumba & 14108 & 113 & 800,96 & 74 \\
\hline Pocho & 5778 & 49 & 848,04 & 45 \\
\hline Minas & 5075 & 68 & 1339,9 & 50 \\
\hline Sobremonte & 5063 & 41 & 809,8 & 21 \\
\hline
\end{tabular}

Fuente: elaboración propia a partir de la población estimada por el INDEC (2020) y localidades del IGN 
Figura 20. Tasa de incidencia cada 100000 habitantes

para el año 2020 según departamentos de la provincia de Córdoba

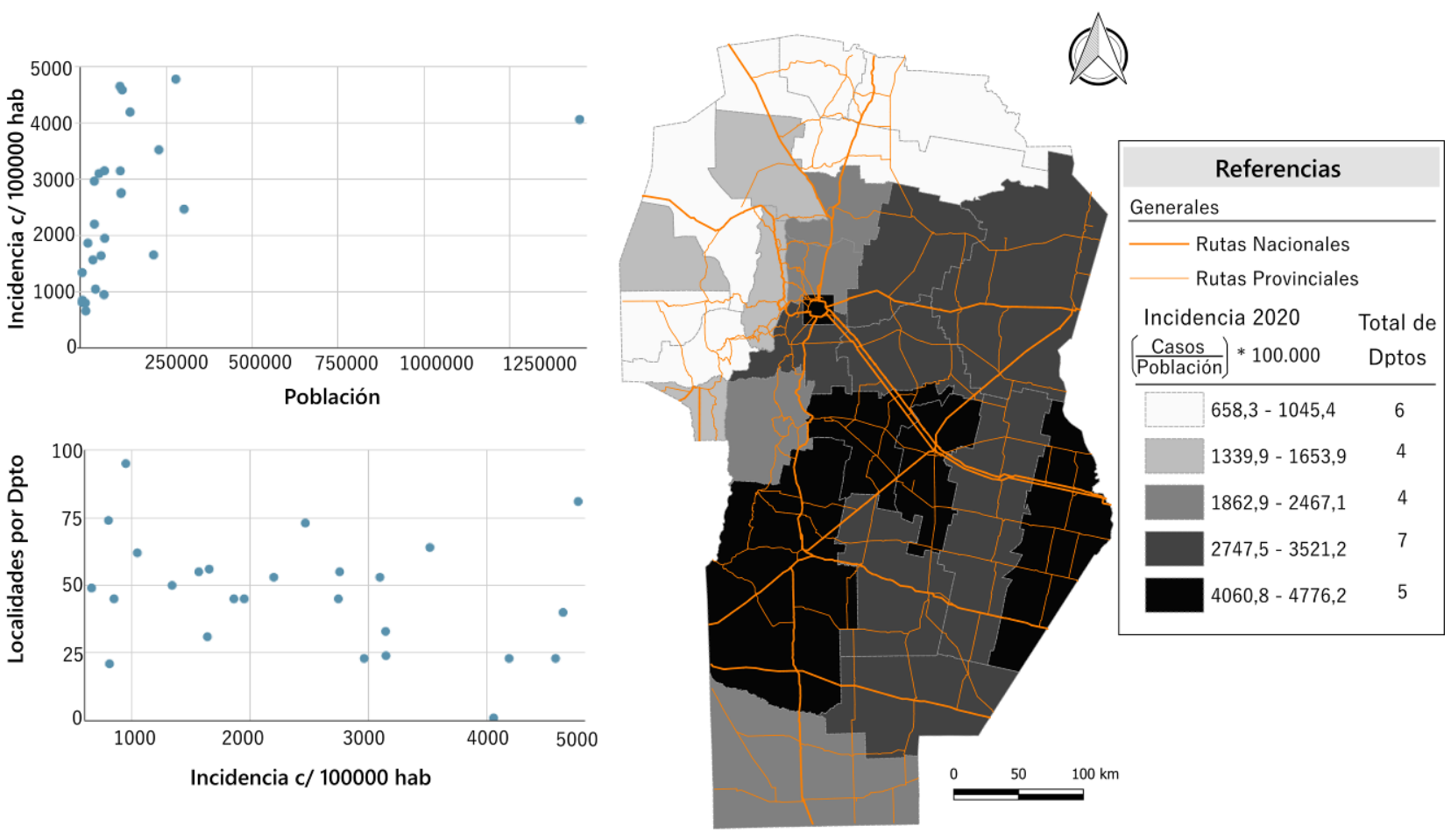

Fuente: elaboración propia

Uno de los factores explicativos de este comportamiento radica en su conectividad. Los cuatro departamentos se encuentran dentro de los principales corredores viales vinculados al comercio nacional e internacional, en donde se registraron los primero brotes de casos en el interior de la provincia durante los periodos II y III. En cada uno de ellos la dinámica de dispersión de la enfermedad entre las localidades que lo integran fue diferencial, en algunos iniciaron en localidades pequeñas para luego repercutir en la localidad cabecera y viceversa (Figura 20). Lo que refuerza la necesidad de análisis espaciales que permitan articular diferentes escalas en el espacio tiempo para comprender su dinámica.

\section{Conclusiones}

Producir información para la toma de decisiones desde y en la pandemia significo un desafío importante que continua en la actualidad. Los resultados entregados en intervalos semanales y en algunos periodos de modo diario, fueron definidos de manera conjunta y coordinada en reuniones permanentes entre el equipo investigación y el Ministerio de Salud de la Provincia de Córdoba. Los mismos se utilizaron para la toma de decisiones y consistieron en cartografía a 
distintas escalas, según el momento de la pandemia, acompañados de informes técnicos, tablas resumen, gráficos estadísticos y de explicaciones presenciales, cuando esta fue requerida.

La metodología de trabajo, fue construida en tiempo real, y se vio condicionada por la calidad de la georreferenciación de los datos de casos detectados, así como también por los recursos disponibles de hardware y software. Para poder efectuar el análisis de concurrencia espacial, se requiere de datos fiables y rigurosos, que localicen correctamente a los individuos contagiados, así como también una capacidad de procesamiento de hardware elevada, que permita ejecutar la intersección de las áreas de los recorridos peatonales de cada una de las personas detectadas como infectadas.

Los cortes temporales para el análisis de la evolución territorial del virus, se fueron ajustando a los fines de las decisiones que se requerían y a partir de indicadores epidemiológicos en un contexto de trabajo interdisciplinario: por grupo de 5 días, semana epidemiológica, quincenal o mensual. La escala de análisis se trabajó en el mismo sentido: por barrio, localidad, pedanía, departamento, corredores viales, áreas definidas con brotes de COVID-19; según los datos y la estrategia de prevención y control in situ sobre la que se requería la información.

Las principales limitaciones que se debieron sortear, fueron la ausencia o parcialidad de bases de datos geolocalizadas de calidad, tanto para la capital provincial como en las localidades del interior. En éstas últimas, recurrentemente eran inexistentes como por ejemplo, la red vial con altura y nombre de las calles, los barrios, establecimientos comerciales etc. Esto evidencio los déficits existentes previos a la pandemia en cuanto a la generación y gestión de bases de datos fiables, tanto a escala local como a escala nacional.

Los resultados que se obtuvieron permiten concluir que a escala regional, la propagación de la COVID-19 se estructuro en torno a corredores definidos por la red vial de mayor circulación, tanto a nivel interprovincial como al interior de la provincia de Córdoba, en relación a los flujos y vínculos existentes entre localidades y, a la jerarquía urbana que ellas presentan.

A nivel intraurbano su comportamiento fue diferencial en relación a las posibilidades de movilidad en el contexto de aislamiento social obligatorio, y luego de las aperturas de actividades, en relación al periodo que estas habían permanecido sin casos. Las localidades que no presentaron casos durante el ASPO, luego de las aperturas fueron las que registraron incrementos más pronunciados en periodos cortos de tiempo. Ejemplo de ello fue la localidad de los Surgentes, los análisis posteriores de nexos epidemiológicos dieron cuenta de que ello 
ocurrió por un relajamiento social en las prácticas de distanciamiento y cuidado mediante el uso de barbijos o tapabocas.

Se puede concluir que la dinámica de contagio, tanto a escala intraurbana e interurbana, refleja la movilidad territorial y los vínculos funcionales que la población poseen dentro del territorio. La metodología de áreas de movilidad peatonal fue eficiente para la detección de nuevos casos en el periodo de aislamiento social obligatorio. A partir de las aperturas de actividades cuando se permitieron las reuniones sociales y la vuelta al modo presencial en los ámbitos laborales, el incremento de casos y las zonas que presentan mayor incidencia se relaciona a los vínculos sociales, funcionales y prácticas de cuidado individual, lo que dificulta las posibilidades de predicción de su expansión territorial, ya que se basa en las conductas particulares de los sujetos de difícil estimación.

Pese a ello, los análisis espacio- temporales de evolución de detección de casos por zonas y localidades permitió detectar aquellas regiones o localidades en donde había una tendencia al incremento de casos, y posibles brotes en relación a las condiciones locales. En el contexto de transmisión comunitaria, la cantidad de casos en valores absolutos deja de ser relevante como un dato en sí mismo en las localidades de mayor jerarquía urbana, ya que nunca se pudo volver al estadio inicial, previo a la circulación comunitaria. Luego del primer pico de la pandemia los casos diarios se estabilizaron en el orden de los 800 casos, por lo que se recurrió a periodos de análisis temporales más amplios, semanales o quincenales, para efectuar comparaciones entre periodos. Sin embargo en las localidades pequeñas, donde los vínculos entre sus habitantes son más estrechos, la aparición de menos de 10 casos en una semana es una señal de alerta.

En síntesis, pese a que la pandemia es un proceso que se desarrolla a escala global, requiere de una mirada y abordaje local que permita dar cuenta de las dinámicas propias de cada territorio dentro de un análisis más amplio de alcance multiescalar.

La pandemia y el análisis articulado interinstitucional (Estado-Estado/Ministerio de Salud Provincial-Universidad Pública) y con especialistas del área de epidemiologia, visibilizo la necesidad en este contexto complejo, de fomentar el diálogo entre las perspectivas geográficas y otras disciplinas vinculadas a la salud, que permitan identificar posibilidades de aplicación y potenciar los resultados. Asimismo, la pandemia motorizo un desafío relevante para la geografía, en tanto disciplina social con una mirada multiescalar de las problemáticas espaciales presentes, 
que cuenta con herramientas potentes de análisis integrales cuantitativos y cualitativos para arribar a resultados integrales y que capturen las dinámicas territoriales existentes.

Agradecimientos: Esta investigación ha sido posible gracias al proyecto de investigación Monitoreo y dinámica territorial de la pandemia (COVID19) en la provincia de Córdoba. Información para la toma de decisiones que fue financiado por el Ministerio de Ciencia Tecnología e Innovación. Argentina (Mincyt) y a la colaboración permanente de la Subsecretaria de prevención y promoción de la salud del Ministerio de Salud de la Provincia de Córdoba.

Declaración responsable: Las autoras declaran que no existe ningún conflicto de interés con relación a la publicación de este artículo. Las tareas se han distribuido de la siguiente manera: el artículo ha sido coordinado por Luciana Buffalo y Ana Laura Rydzewski. Las dos autoras han participado en las definiciones metodológicas, revisión bibliográfica, y en la redacción del artículo. El procesamiento de datos, análisis espacial y cartografía la elaboró Ana Laura Rydzewski. 


\section{Bibliografía}

Agencia Córdoba Turismo (2015). Registro estadístico 28/02 (Unpublished).

Anselin, L. (1995). Local Indicators of Spatial Association - LISA. Geographical Analysis, (27), 93115. https://doi.org/10.1111/1.1538-4632.1995.tb00338.x

Bracamonte P., Maldonado M., Benito N., Bracamonte, J., \& Maldonado P. (2013). Sistema de Transporte, Metrópolis y Territorio. El caso del Área Metropolitana Córdoba, R. Argentina. Ciencia y Tecnología, (13), 95-108.

https: / /dialnet.unirioja.es/servlet/articulo?codigo $=4843854$

Buffalo, L., \& Rydzewski A. (2016). Conflictos territoriales en la periferia sur de la ciudad de córdoba en el siglo XXI. Revista Pensum, (2), 57 80. https://revistas.unc.edu.ar/index.php/pensu/article/view/16432/16299

Buzai, G. D., \& Baxendale, C. A. (2006). Análisis socioespacial con sistemas de información geográfica. Lugar.

Calvo Melero, M., \& Palanques Salmerón, M. (2017). Inteligencia de Ubicación con Sistemas de Información Geográfica. Universidad del País Vasco, España. http://hdl. handle.net/10810/29629.

Chasco Yrigoyen, C. (2010). Análisis estadístico de datos geográficos en geomarketing: el programa GeoDa. Distribución y Consumo, (2), 3445. https://www.mapa.gob.es/ministerio/pags/biblioteca/revistas/pdf_DYC/DYC_2006_86 34_45.pdf

Chinazzi, M., Davis, J., Ajelli, M., Giovannini, C., Litvinova, M., Merler, S., Pastoe, A., Mu, K., Rossi, L., Sun, K., Viboud, C., Xiong, X., Yu, H., Halloran, M., Longini, I., \& Vespignani A. (2020). The effect of travel restrictions on the spread of the 2019 novel coronavirus (COVID-19). Outbreak Science, (368), 395. https://doi.org/10.1126/science.aba9757

CNPHYV (2010). Censo Nacional de Población, hogar y vivienda de Argentina. In Instituto Nacional de Estadística y Censos de la República Argentina. https://www.indec.gob.ar/indec/web/Nivel4-Tema-2-41-135

Cromley, E., \& McLafferty, S. (2011). GIS and Public Health (2 $2^{\text {th }}$ ed.). The Guilford Press. 
DNU (2020). Decreto de necesidad y urgencia del poder ejecutivo nacional. In Información Legislativa y Documental. Ministerio de Justicia y Derechos humanos Argentina (260/2020). http://servicios.infoleg.gob.ar/infoleglnternet/verNorma.do?id=335423

Elliott, P., \& Wartenberg, D. (2004). Spatial epidemiology: current approaches and future challenges. Environmental health perspectives, 112(9), 998-1006.

https://doi.org/10.1289/ehp.6735

Franch Pardo, I., Napoletano, B. M., Rosete Verges, F., \& Billa, L. (2020). Spatial analysis and GIS in the study of COVID-19. A review. The Science of the total environment, 739, 140033. https://doi.org/10.1016/j.scitotenv.2020.140033

Fuenzalida, M., \& Cobs, V. (2013). La perspectiva del análisis espacial en la herramienta sig: una revisión desde la geografía hacia las ciencias sociales. Persona y Sociedad, 27(3), 3352. https://repositorio.uahurtado.cl/bitstream/handle/11242/3665/27-3-2013-

\section{3. pdf? sequence $=1 \&$ is Allowed $=y$}

Gómez, N. (2021) Mapa de calor del COVID-19 en Santa Fe: análisis provincial y metropolitano. Posición, (5), 1-15. https://ri.conicet.gov.ar/handle/11336/135691

Heywood, D. I., Cornelius, S., \& Carver, S. (1998). An introduction to geographical information systems. Addison Wesley Longman.

INDEC (2020). Proyecciones y estimaciones de población. In Instituto Nacional de Estadísticas y Censos de la República Argentina. https://www.indec.gob.ar/indec/web/Nivel3-Tema-2-24

Iñigues Rojas, L. (1998). Geografía y salud: temas y perspectivas en América Latina. Cadernos de Saúde Pública, 14(4), 701-711. https://doi.org/10.1590/S0102-311X1998000400012

Iñiguez Rojas, L. B., \& Barcellos, C. (2014). La cartografía en salud pública: viejos problemas y nuevas oportunidades. Revista Do Departamento de Geografia, (spe), 390412. https://doi.org/10.11606/rdg.v0i0.539

Johnston, R. J., G., Gregory, G. P., \& Watts, M. (Eds) (2000). The dictionary of human geography $\left(4^{\text {th }}\right.$ ed.). Blackwell.

La Macchia, M., Linares, S., Tisnés, A., Picone, N., Ortmann, M., Franzoia Mos, D., Rocha, H., \& Ramírez, L. (2020, October 15). Infraestructura de datos espaciales de la FCH- UNICEN para la gestión sanitaria frente al COVID-19 (1 - 10). In Jornadas Virtuales de Academia y Ciencia de IDERA. Argentina. http://hdl. handle.net/11336/132312 
MSN (2020). Boletín integrado de vigilancia epidemiológica N492 SE14. Ministerio de Salud de la Nación. https://bancos.salud.gob.ar/recurso/boletin-integrado-de-vigilancia-n492-se14$\underline{30042020}$

MSN (2021). Reporte $n^{\circ}$ 17. Provincia de Córdoba. Proyecto Argentino Interinstitucional de genómica Ministerio de Salud de la Nación. https://www.argentina.gob.ar/sites/default/files/reporte_ndeg17-proyecto_paiscordoba-19-03-2021.pdf

Nakaya, T. (2000). An information statistical approach to the modifiable areal unit problem in incidence rate maps. Environment \& Planning, (32), 91-109. https://doi.org/10.1068/a31145

OMS (2020). Documento de políticas La Covid-19 en un mundo urbano. Organización Mundial de la Salud.

https://www.un.org/sites/un2.un.org/files/covid-19_in_an_urban_world_spanish.pdf

Openshaw, S. (1994). Two exploratory space-time attribute pattern analyzers relevant to GIS. In S. Fotheringham and P. Rogerson (Eds.), Spatial Analysis and GIS (pp.83-104). Taylor \& Francis.

Openshaw, S. (1983). The modifiable areal unit problem.

GeoBooks. https://www.uio.no/studier/emner/sv/iss/SG09010/openshaw1983.pdf

Oseias Martinuci, S. (2019). Cartografias da saúde: alguns apontamentos (6 a 21) In A. Werneck \& E. Ribeiro (Coords.), Cartografia na geografía da saúde. Metodologas e técnicas (pp. 6-21). Instituto federal Catarinense. http://dx.doi.org/10.21166/9788556440433

Perles Rosello, M. J., Sortino Barrionuevo, J. F., Cantarero Prados, F. J., Castro Noblejas, H., De la Fuente Roselló, A.L., Orellana Macías, J.M, Reyes Corredera, S. \& Mérida Rodríguez, M. (2020). Propuesta metodológica para la elaboración de una cartografía de riesgo de COVID19 en entornos urbanos (Unpublished report). Universidad de Málaga. https://riuma.uma.es/xmlui/bitstream/handle/10630/19477/Metodolog\%C3\%ADa\% 20Cartograf\%C3\%ADa\%20Riesgos\%20COVID-19.pdf? sequence=1\&isAllowed=y

Perles, M.-., Sortino, J. F., \& Mérida, M. F. (2021). The Neighborhood Contagion Focus as a Spatial Unit for Diagnosis and Epidemiological Action against COVID-19 Contagion in Urban Spaces: A Methodological Proposal for Its Detection and Delimitation. International Journal of Environmental Research and Health, 3145. http://doi.org/10.3390/ijerph18063145 
PET (2011). Argentina Urbana. Lineamientos para una política nacional de urbanización. Plan Estratégico Territorial Avance II: Argentina Urbana. In Ministerio de Planificación Federal, Inversión Pública y Servicios. https://www.mininterior.gov.ar/planificacion/pdf/AS_13663122171.pdf

Ramírez, L. (2020). Evolución, distribución y difusión del COVID-19 en Argentina: primer mes. Posición, 3, 1-12. https://posicionrevista.wixsite.com/inigeo

RENABAP (2016) Registro Nacional de Barrios Populares .In Ministerio de Desarrollo Social, Secretaría de Integración Socio Urbana. https://datos.gob.ar/dataset/desarrollo-social-registronacional-barrios-populares.

Romero Jimenez C, Tisnes A., \& Linares, S. (2020). Modelo de simulación del COVID-19 basado en agentes. Aplicación al caso argentino. Posición, (3), 1 -

22. https://posicionrevista.wixsite.com/inigeo

Rushton G. (2003). Public health, GIS, and spatial analytic tools. Annual review of public health, (24), 43-56. https://doi.org/10.1146/annurev.publhealth.24.012902.140843

Santos, M. (1996). De la totalidad al lugar. Oikos-Tau.

Santos, M. (1997). Técnica, Espago, Tempo. Globalizagao e meio tecnico-cientifico informacional. Editora Hucitec.

Santos, M. (1999). O território e o saber local: algumas categorias de análise. Cadernos IPPUR, 13(2), 15-26. https://revistas.ufrj.br/index.php/ippur/issue/downlo\%20ad/277/86

Siabato, W., \& Guzmán-Manrique, J. (2019). La autocorrelación espacial y el desarrollo de la geografía cuantitativa. Cuadernos de Geografía: Revista Colombiana de Geografía, 28(1), 1 22. https://doi.org/10.15446/rcdg.v28n1.76919

Snow, J. (1854). Home page. John Snow Society. www.johnsnowsociety.org

Tecco, C. (2001). Regiones metropolitanas ¿fragmentación política administrativa y gestión asociada? Aportes para una discusión sobre la Región Metropolitana Córdoba. Administración Pública y Sociedad, (14), 69-79. https://rdu.unc.edu.ar/handle/11086/11663

Techo (2016). Relevamiento de asentamientos informales. Techo.org http://datos.techo.org/dataset/argentina-relevamiento-asentamientos-informales-2016 UptonGy Fingleton, B. (1985). Spatial Data Analysis by Example: Point Pattern and Quantitave Data, 1. J. Wiley \& Sons. 